FEDERAL

RESERVE

BANK of

ST. LOUIS
RESEARCH DIVISION

Working Paper Series

\title{
Talent, Labor Quality, and Economic Development
}

\author{
German Cubas, \\ B. Ravikumar \\ and \\ Gustavo Ventura
}

\author{
Working Paper 2013-027D \\ https://doi.org/10.20955/wp.2013.027
}

May 2015

\author{
FEDERAL RESERVE BANK OF ST. LOUIS \\ Research Division \\ P.O. Box 442 \\ St. Louis, MO 63166
}

The views expressed are those of the individual authors and do not necessarily reflect official positions of the Federal Reserve Bank of St. Louis, the Federal Reserve System, or the Board of Governors.

Federal Reserve Bank of St. Louis Working Papers are preliminary materials circulated to stimulate discussion and critical comment. References in publications to Federal Reserve Bank of St. Louis Working Papers (other than an acknowledgment that the writer has had access to unpublished material) should be cleared with the author or authors. 


\title{
Talent, Labor Quality, and Economic Development
}

\author{
German Cubas, B. Ravikumar, and Gustavo Ventura*
}

May 2015

\begin{abstract}
We develop a theory of labor quality based on (i) the division of the labor force between unskilled and skilled workers and (ii) investments in skilled workers. In our theory, countries differ in two key dimensions: talent and total factor productivity (TFP). We measure talent using the observed achievement levels from the Programme for International Student Assessment (PISA) scores. Our findings imply that the quality of labor in rich countries is about twice as large as the quality in poor countries. Thus, the implied disparities in TFP levels are smaller relative to the standard growth model using a Mincerian measure of labor quality. In our model, the resulting elasticity of output per worker with respect to TFP is about 2 .

Keywords: Economic Development, TFP, PISA, Labor Quality. JEL Classification: O11, O40, E10.
\end{abstract}

${ }^{*}$ University of Houston, Federal Reserve Bank of St. Louis, and Arizona State University, respectively. We thank the Editor and two referees, Hector Chade, Juan Carlos Cordoba, Andrés Erosa, Oksana Leukhina, Diego Restuccia, Andrés Rodriguez-Clare, and Todd Schoellman for their useful comments and suggestions. We also thank the seminar participants at APET-Seattle, Central Bank of Uruguay, Concordia, Copenhagen, Di Tella, Durham, Econometric Society Meetings (Asia), Economic Development Conference at Toronto, FCS-Uruguay, Georgia, Human Capital Conference (ASU), ITAM Summer Camp, LACEA Meetings, Macroeconomics Across Time and Space Conference, Research in Economic Dynamics Workshop (Barcelona), SED Meetings, Sabanci, Stony Brook, Texas A\&M, UBC, Universidad de Montevideo, USC, and Yale. Judy Ahlers provided excellent editorial assistance. The usual disclaimer applies. The views expressed in this article are those of the authors and do not necessarily reflect the views of the Federal Reserve Bank of St. Louis or the Federal Reserve System. 


\section{Introduction}

It is well known that the observed cross-country differences in output per worker are large. For example, the richest countries in the world economy are about 30 to 40 times richer than the poorest countries. Klenow and Rodriguez-Clare (1997), Prescott (1998), Hall and Jones (1999), McGrattan and Schmitz (2000), and Parente and Prescott (2000), among others, have documented that these differences are primarily due to differences in total factor productivity $(\mathrm{TFP})$.

To calculate the relative importance of TFP, researchers measure the cross-country differences in the quality of workers, or labor quality for short. Traditionally, labor quality has been measured using observations on schooling and Mincerian returns to schooling. Such measurements account for a small fraction of the differences in output per worker; see Caselli (2005) for a review. However, what if TFP differences include unmeasured labor quality differences? Recent work follows two approaches to quantify this unmeasured component. One approach uses labor earnings of immigrants from different countries working in the U.S. labor market to quantify cross-country differences in labor quality. Hendricks (2002) and Schoellman (2011) are examples of this approach. The other approach involves developing theories of labor quality based on unobserved individual heterogeneity and disciplining the key parameters describing the heterogeneity with observations of U.S. labor earnings. Erosa, Koreshkova, and Restuccia (2010) is an example of this approach.

In this paper, we take an alternative approach to the measurement of labor quality and the resulting implications for the importance of TFP. We use direct observations of the achievements of individuals prior to their entry into the labor force as an exogenous input to a theory of labor quality. We develop a parsimonious framework in which countries differ in two key dimensions - talent and TFP — and in which individuals endogenously become unskilled or skilled workers.

We construct a measure of talent using the observed test scores from the Programme for International Student Assessment (PISA). We then use our measure of talent and our model to construct a measure of labor quality. Our guiding assumption is that individual skills by the end of compulsory schooling are embodied in PISA scores. In this context, we quantify the role of PISA scores relative to TFP in accounting for cross-country differences in output per worker. Specifically, we ask two questions: How large are the differences in labor quality 
across countries? And what are the resulting magnitudes of TFP differences?

PISA is an internationally standardized assessment of student achievement organized and conducted by the OECD. The tests are administered to 15-year-old students and provide a useful quantification of skills toward the end of the schooling period. One advantage of using PISA scores for our purposes is the common assessment of young people across countries near the end of compulsory schooling. The PISA tests students of the same age in each country independently of the structure of national school systems. By contrast, other studies focus on testing students in specific grades, which may be distorted by the fact that countries differ in their grade-entry ages and grade-repetition rules. Another advantage of PISA is that the tests are constructed to evaluate a range of relevant skills that capture how well young adults are prepared to meet future work demands by being able to analyze, reason, and communicate their ideas effectively. While previous studies are curriculum based, PISA tests the young adults' ability to "use their knowledge and skills in order meet real-life challenges" (OECD, 2001, p. 16). By design, PISA provides a single, comparable measure of skills of individuals prior to their entry into the labor force for each country.

Our model has a representative household with a continuum of members. The members are heterogeneous and are born with some innate efficiency units of labor or talent. The household divides its members into two groups: skilled workers and unskilled workers. Converting a member of the household into a skilled worker is costly: It requires time (forgone earnings) and goods. As more goods are invested, the resulting quality of each skilled worker is higher. Given our guiding assumption, the household invests only in the skilled workers; the quality of an unskilled worker is simply his or her innate talent. The production technology uses capital, unskilled labor, and skilled labor as factors of production. Thus, while the distribution of talent is exogenous in our model, labor quality is endogenous. When the elasticity of substitution between unskilled labor and skilled labor is in the empirically plausible range, we show that an increase in TFP increases the fraction of skilled workers as well as the quality of skilled workers. In this sense, differences in TFP have not only the standard effects on output-per-worker differences, but also a novel effect through differences in labor quality.

In a sample of 59 countries, we construct a measure of talent using the observed PISA score. We calibrate two other critical parameters in the model - the importance of goods 
in the enhancement of the quality of skilled workers and the share of unskilled labor in the aggregate technology. We use only the U.S. data to match the observed expenditures per tertiary student as a fraction of GDP per worker and the fraction of unskilled workers (those with a secondary education or less).

We find substantially larger differences in labor quality across countries than standard analyses based on Mincerian returns. Using Mincerian returns, labor quality in the poorest 10 percent of the countries in our sample is about 86 percent of the quality in the richest 10 percent of the countries. In our model, this labor-quality ratio is only about 45 to 55 percent. In the calculation of the Mincerian labor quality, workers in different countries with the same years of schooling are considered to be of the same quality. In contrast, our model treats them differently based on the distribution of the PISA score for the country. For instance, the average PISA score among workers with a high school education or less in the U.S. is nearly 33 percent higher than that in the Kyrgyz Republic - the country with the lowest mean PISA score and lowest output per worker in our sample. In addition, the investment in skilled workers in our model increases the quality of the average U.S. skilled worker even more. Our finding on labor quality differences is similar to that in Schoellman (2011), who also treats workers in different countries with the same years of schooling differently and uses data on immigrants in the U.S. to infer variation in labor quality. He concludes that labor quality differences between poor and rich countries are twice as large as those under conventional measures using Mincerian returns.

As a result of the larger implied differences in labor quality, TFP differences from our model are smaller than those from standard analyses. Stated differently, output per worker in our model reacts more to changes in TFP. The resulting elasticity of output per worker with respect to TFP is around 2.1 in our model. The TFP elasticity is 1.5 in the standard onesector growth model and roughly 1.7 under a measure of labor quality based on Mincerian returns, as this variable is correlated with output per worker.

Our paper is part of the literature on the determinants of cross-country income differences and, in particular, on the amplification of distortions and TFP differences via human capital. Examples include Bhathacharya, Guner, and Ventura (2013), Cordoba and Ripoll (2013), Erosa et al. (2010), Manuelli and Seshadri (2010), and Restuccia (2001). Given our emphasis, Manuelli and Seshadri (2010) and Erosa et al. (2010) are closely related to our pa- 
per. Manuelli and Seshadri (2010) develop a model of labor quality based on human capital acquisition in early childhood and over the life cycle. In their model, investments of goods in human capital formation play a central role, especially in early childhood. Cross-country differences in TFP thus lead to differences in labor quality. They find that small differences in TFP lead to large differences in output per worker; the TFP elasticity of output per worker in their model is roughly 6.5. Erosa et al. (2010) develop a model of intergenerational transmission of inequality. In their model, a child's human capital is a function of goods invested and is affected by parental human capital. TFP differences then amplify output-per-worker differences via endogenous human capital differences. Using data on earnings inequality and its persistence across generations to calibrate their model, these authors find a TFP elasticity of output per worker around 2 .

Several remarks are in order. First, our TFP elasticity of output per worker is almost the same as that in Erosa et al. (2010), even though our model is different and more parsimonious. ${ }^{1}$ Second, similar to Manuelli and Seshadri (2010) and Erosa et al. (2010), the TFP elasticity in our model depends on the importance of goods in enhancing the quality of skilled workers. For instance, if we double the importance of goods, the TFP elasticity in our model increases from 2.1 to more than 3. Finally, unlike the models in Manuelli and Seshadri (2010) and Erosa et al. (2010), our model is clearly silent on the early acquisition of skills since the agents enter our model with a PISA score at age 15. Nonetheless, one advantage of our approach is that differences across countries at the point of entry into the labor force are disciplined directly by observed differences in PISA scores. Regardless of the role of TFP and other factors in early human capital formation, we view their effects as summarized by the observed PISA scores.

Our paper is also related to a recent body of work that uses test scores in reduced-form analyses of economic growth in a cross section of countries. Hanushek and Kimko (2000), Hanushek and Woessmann (2008), and Hanushek and Woessmann (2012) are examples of these papers. The main finding from this literature is a substantial impact of cognitive skill differences, measured by test scores, on long-run growth rates. In Section 9.1 we discuss how our findings are connected with those emerging from such papers.

Our paper is organized as follows. Section 2 presents the data used in the paper, with

\footnotetext{
${ }^{1}$ We present a longer discussion of the relationship of our paper to Erosa et al. (2010) in Section 7.
} 
emphasis on data from the PISA program. Section 3 develops the theoretical framework. Section 4 discusses the parameterization of the model and its mapping to data. In Section 5, we perform a number of experiments to highlight how the model works. Section 6 presents the main quantitative findings of the paper. In Section 7, we evaluate how our findings compare with those from previous analyses. In Section 8, we study the implications of our framework for skill premia. The discussion in Section 9 puts our findings in perspective by offering some additional exercises. Finally, Section 10 concludes.

\section{Data}

We summarize below the central aspects of data that pertain to our study. We concentrate on cross-country PISA scores, enrollment rates, the division of labor between unskilled and skilled workers, and corresponding observations on output per worker.

\section{$2.1 \quad$ PISA}

The PISA study is a systematic assessment of students across countries that was jointly developed by participating economies. In this paper, we use the wave of PISA assessments conducted in 2009. The PISA tests abilities in mathematics, reading, and science. The study is organized and conducted by the OECD, ensuring as much comparability among participants as possible.

The PISA sampled students between 15 years and 3 months of age and 16 years and 2 months of age. Only students enrolled in an educational institution are sampled, regardless of the grade level or type of institution. The average age of OECD country students participating in PISA was 15 years and 8 months and varied by a maximum of only 2 months among the participating countries. ${ }^{2}$

The performance tests last two hours and are taken using paper and pencil. They include both multiple-choice items and questions that require students to construct their own responses. The PISA aims to test not merely the mastery of the school curriculum, but also

\footnotetext{
${ }^{2}$ The PISA sampling procedure ensured that a representative sample of the target population was tested in each country. Most PISA countries used a two-stage stratified sampling technique. The first stage consists on drawing a random sample of schools; in the second stage, students are randomly sampled in each of these schools to ensure that each 15-year-old student in a school has an equal probability of selection. This procedure typically yielded a sample of between 4,500 and 10,000 students per country.
} 
important knowledge and skills needed in adult life (OECD, 2000, p. 8). All subjects were tested at different levels of difficulty to represent a coherent and comprehensive indicator of students' abilities. Using item response theory, the PISA mapped each subject's performance on a scale with an international mean of 500 test-score points across the OECD countries and an international standard deviation of 100 test-score points.

We consider 59 of the 65 countries that participated in the PISA 2009 study. These countries are listed in Table 1 with their corresponding codes. We exclude China-Shangai and China-Taipei from the list of PISA participating countries, given that the test was administered in only one urban area in these two countries. We also exclude Liechtenstein, Montenegro, and Azerbaijan, as we lack data on the composition of the labor force for these countries. Finally, we also exclude Qatar due to its outlier character in terms of output per worker.

We report results using the math test score. We note, however, that the correlation of student performance among the three subjects is substantial: 0.95 between reading and math, 0.98 between reading and science, and 0.97 between math and science.

\section{$2.2 \quad$ Related Data}

To characterize facts on the cross-country relationship between test scores and economic development, we also use country-level data on GDP per worker in 2007 (purchasing power parity [PPP]) from the Penn World Tables 7.0. Since the tests are administered to 15-yearolds and in some countries a nontrivial fraction of youths this age do not attend school, we also document and subsequently use the enrollment rates in school at age 15 as provided by the PISA study.

Our framework has implications for the division of the labor force between skilled and unskilled workers. We define skilled individuals as those with strictly more than a high school education, whereas unskilled individuals are their complement. We consider the fraction of individuals in each group among the population 15 years and older. For the measurement of these concepts, we use data from Barro and Lee (2010). 


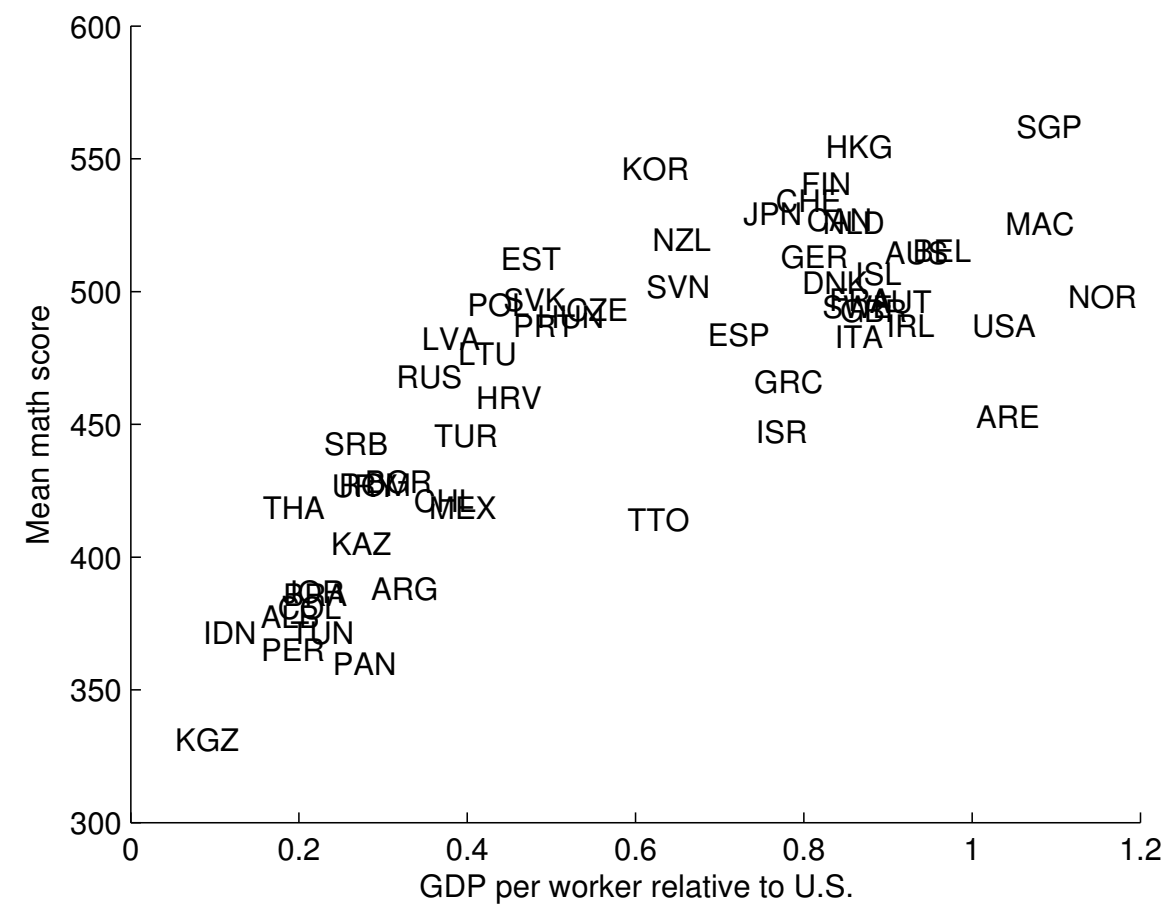

Figure 1: Mean PISA scores (math) and GDP per worker.

\subsection{Facts Summary}

Table 2 and Figures 1, 2, and 3 summarize the main features from the data. First, there are substantial differences in mean PISA scores across countries. While the cross-country average of the mean scores is 464, the standard deviation is 57 . In the distribution of mean scores across countries, the ratio of the 90th percentile to the 10th percentile is about 1.4. Similarly, the maximum gap is a factor of about 1.7 (between Singapore and the Kyrgyz Republic).

Second, there is a strong and positive relationship between mean PISA scores and output per worker. Richer countries have, on average, higher achievement scores. As Table 1 indicates, the correlation between the mean math score and output per worker is almost 0.8. Differences in output per worker, however, dwarf observed differences in PISA scores. For instance, the gap between the U.S. and Argentina is a factor of nearly 1.3 in mean PISA scores, whereas the gap in output per worker is about 3.5.

Third, there is a positive relationship between enrollment rates and output per worker, 


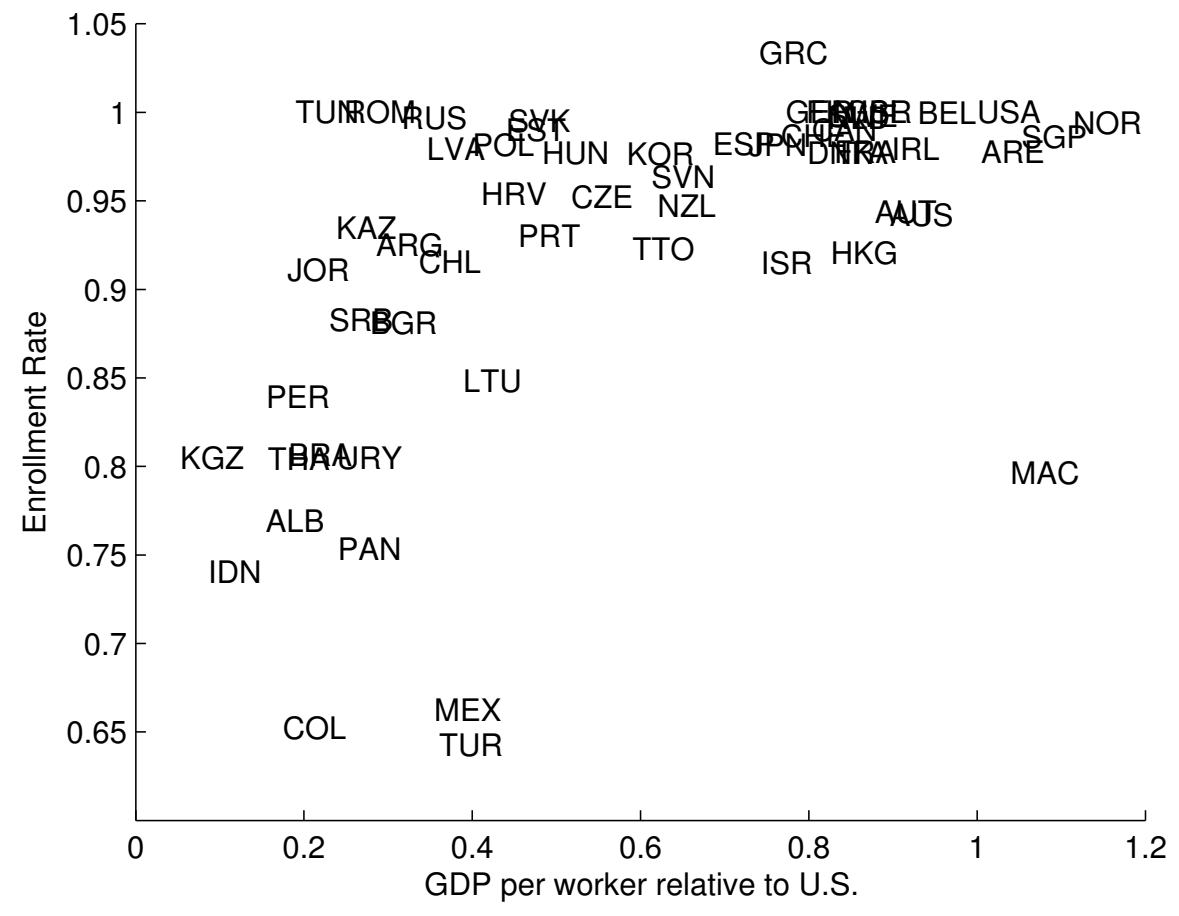

Figure 2: Enrollment rates (at age 15) and GDP per worker.

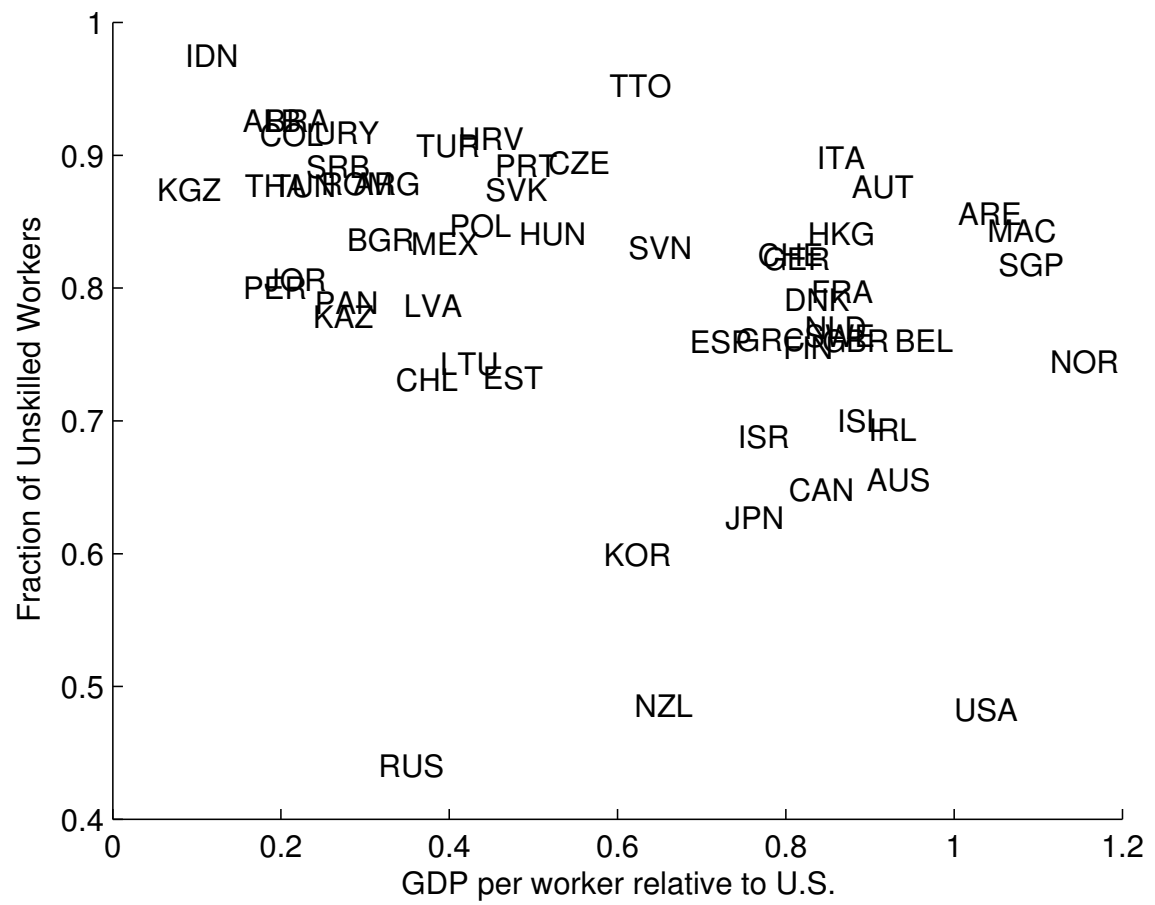

Figure 3: Fraction of unskilled workers (high school education or less) and GDP per worker. 
with a correlation of about 0.50 . Recall that the PISA tests are administered only to those enrolled in schools. About 80 percent of individuals at age 15 attend school in Uruguay, whereas all of them attend school in Finland and the U.S. At the bottom of the distribution, only about 64 percent of 15 -year-olds attend school in Turkey.

Finally, the data reveal a negative relationship between output per worker and the fraction of unskilled workers. While about 98 percent of workers in Indonesia (the maximum in our sample) are unskilled with an output per worker level of about 9 percent of the U.S., only 48 percent of U.S. workers are unskilled. That is, more than 50 percent of U.S. workers have more than a high school education. The correlation between the fraction of unskilled workers and output per worker is about -0.33 .

\section{Theoretical Framework}

There is a single representative household in the economy. The household at time $t$ has a continuum of members of total size $L_{t}$, who value only consumption. The size of the household grows at the constant rate $\left(g_{L}\right)$. The household is infinitely lived and maximizes

$$
\sum_{t=0}^{\infty} \beta^{t} L_{t} \log \left(C_{t} / L_{t}\right)
$$

where $\beta \in(0,1)$ and $C_{t}$ denotes total household consumption at date $t$.

Endowments Each household member is born with $z$ units of talent. The talent is distributed with support in $Z=[0, \bar{z}]$, with $\operatorname{cdf} G(z)$ and density $g(z)$. Household members have one unit of time that is supplied inelastically. Each household member can be a skilled or unskilled worker. We describe this decision and the associated incomes in detail below. The household is also endowed with an initial capital stock $K_{0}>0$.

Technology There is a representative firm that operates a constant returns to scale technology. This technology requires three inputs: capital $K$, and two types of labor services: skilled labor $S$ and unskilled labor $U$. Output $(Y)$ is given by

$$
Y=F(K, U, S ; A)=A K^{\alpha}\left[\mu U^{\rho}+(1-\mu) S^{\rho}\right]^{(1-\alpha) / \rho},
$$


where $A$ denotes the TFP parameter and $\rho \in(-\infty, 1)$. The elasticity of substitution between skilled and unskilled labor is $1 / 1-\rho$. Output per worker, $y \equiv Y / L$, is given by

$$
y=A k^{\alpha} l^{1-\alpha}
$$

with $l \equiv\left[\mu u^{\rho}+(1-\mu) s^{\rho}\right]^{1 / \rho}, u \equiv U / L$, and $s \equiv S / L$. We subsequently refer to $l$ as labor quality.

The representative firm faces competitive rental prices $R, W_{S}$, and $W_{U}$ for the use of capital, skilled labor, and unskilled labor, respectively. Capital depreciates at the rate $\delta$.

The Household Problem We assume that the segregation of individuals by skill level is costly. This segregation applies only to newborns and cannot be changed once a household member has been assigned to either pool. Converting one newborn into a skilled worker requires goods and time. If a newborn household member is selected for the unskilled labor pool at $t$, her talent is contemporaneously transformed into efficiency units of unskilled labor and her income is given by $W_{U, t} z$.

If she instead becomes part of the skilled pool, it takes one period to provide skilled labor services and the household has to forgo her earnings for one period. The household invests $x_{t}$ consumption goods to augment her talent. Investing $x_{t}$ implies that her talent is augmented by the factor $h_{t+1}$, where

$$
h_{t+1}=B x_{t}^{\phi}
$$

with $\phi \in(0,1)$ and $B$ is a parameter governing the relative efficiency of goods investment in augmenting talent. Her contribution to the household's income is then given at $t+1$ by $W_{S, t+1} z h_{t+1}$. It follows that only individuals with sufficiently high levels of talent become skilled. Given rental prices, there exists a unique threshold $\hat{z}_{t}$ such that newborn household members with talent below this threshold are unskilled workers at $t$, and those with talent above the threshold become skilled workers from $t+1$ on.

If there are $N_{t} \equiv g_{L} L_{t-1}$ newborns in period $t$ and $N_{t}\left(1-G\left(\hat{z}_{t}\right)\right)$ newborns become skilled, the household invests a total of $N_{t} x_{t}\left(1-G\left(\hat{z}_{t}\right)\right)$ goods at $t$ to augment their talent by a factor $h_{t+1}$. Then, the aggregate quantities of unskilled and skilled labor evolve according to 


$$
\begin{gathered}
U_{t}=U_{t-1}+\underbrace{\underbrace{N_{t} \int_{0}^{\hat{z}_{t}} z g(z) d z}_{t} \text { and }}_{\text {Additions to unskilled labor }} \\
S_{t}=S_{t-1}+\underbrace{N_{t-1} h_{t} \int_{\hat{z}_{t-1}}^{\bar{z}} z g(z) d z}_{\text {Additions to skilled labor }} .
\end{gathered}
$$

Note that at any time $t, U_{t}+S_{t}$ is not equal to $L_{t}$, since $U_{t}$ is the quality of unskilled labor and $S_{t}$ is the quality of skilled labor, whereas $L_{t}$ is the size of the household at time $t$.

We also assume that the household's cost for transforming one unit of consumption into investment is potentially different from 1 . We represent these costs by an exogenous barrier to capital accumulation, $p_{t} \geq 1$.

The household's problem is to choose (i) the sequences of consumption, (ii) the fractions of household members who are skilled and unskilled, (iii) the quantity of goods invested in augmenting new skilled members' talent, and (iv) the amount of capital to carry over to the next period. Formally, the household's problem is to select $\left\{C_{t}, I_{t}, \hat{z}_{t}, x_{t}\right\}_{0}^{\infty}$ to maximize (1) subject to (4), (5), and (6),

$$
\begin{gathered}
C_{t}+I_{t}+N_{t}\left(1-G\left(\hat{z}_{t}\right)\right) x_{t}=\left(W_{U, t} U_{t}+W_{S, t} S_{t}\right)+R_{t} K_{t} \\
K_{t+1}=(1-\delta) K_{t}+\frac{I_{t}}{p_{t}}
\end{gathered}
$$

and

$$
N_{0}, S_{0}, U_{-1}, K_{0}>0 .
$$

The solution to the household's problem is characterized by the following first-order conditions:

$$
\begin{gathered}
\frac{p_{t}}{C_{t} / L_{t}}=\beta \frac{\left[R_{t+1}+(1-\delta) p_{t+1}\right]}{C_{t+1} / L_{t+1}}, \\
\frac{W_{U, t} \hat{z}_{t}+x_{t}}{C_{t} / L_{t}}=\beta \frac{W_{S, t+1} \hat{z}_{t} B x_{t}^{\phi}}{C_{t+1} / L_{t+1}} \text {, and } \\
\frac{1-G\left(\hat{z}_{t}\right)}{C_{t} / L_{t}}=\beta \frac{W_{S, t+1}\left(\int_{\hat{z}_{t}}^{\bar{z}} z g(z) d z\right) \phi B x_{t}^{\phi-1}}{C_{t+1} / L_{t+1}} .
\end{gathered}
$$


Condition (7) is the standard Euler equation for capital accumulation. Condition (8) states that the discounted compensation of the household member with marginal skill $\hat{z}_{t}$ at $t$, weighted by the marginal utility of consumption at $t+1$, must be equal to the compensation of an unskilled household member plus the cost of skill augmenting, $x_{t}$, weighted by the marginal utility of consumption at $t$. Finally, condition (9) states that the marginal cost of investing one unit of the consumption good in the quality of a skilled worker must equal its discounted marginal benefit. This benefit depends on the rental price of skilled labor at $t+1$ and the "raw" addition of a member to the pool of skilled labor at $t+1, \int_{\hat{z}_{t}}^{\bar{z}} z g(z) d z$.

Equilibrium In competitive equilibrium, the markets must clear and factors are paid their marginal products. Equilibrium in the markets for unskilled and skilled labor implies

$$
\begin{aligned}
& U_{t}^{*}=U_{t-1}^{*}+N_{t} \int_{0}^{\hat{z}_{t}^{*}} z g(z) d z \text { and } \\
& S_{t}^{*}=S_{t-1}^{*}+N_{t-1} h_{t}^{*} \int_{\hat{z}_{t-1}^{*}}^{\bar{z}} z g(z) d z,
\end{aligned}
$$

for all $t=0,1,2, \ldots$, where an asterisk above a variable denotes its equilibrium value. Equilibrium in the goods market implies

$$
C_{t}^{*}+I_{t}^{*}+N_{t}\left(1-G\left(\hat{z}_{t}^{*}\right)\right) x_{t}^{*}=Y_{t}^{*}
$$

Factor prices equal

$$
\begin{gathered}
W_{U, t}^{*}=\frac{\partial F\left(K_{t}^{*}, S_{t}^{*}, U_{t}^{*}\right)}{\partial U_{t}} \\
W_{S, t}^{*}=\frac{\partial F\left(K_{t}^{*}, S_{t}^{*}, U_{t}^{*}\right)}{\partial S_{t}} \\
R_{t}^{*}=\frac{\partial F\left(K_{t}^{*}, S_{t}^{*}, U_{t}^{*}\right)}{\partial K_{t}}
\end{gathered}
$$

for all $t=0,1,2, \ldots$

A competitive equilibrium is a collection of sequences $\left\{C_{t}^{*}, K_{t}^{*}, \hat{z}_{t}^{*}, x_{t}^{*}, W_{U, t}^{*}, W_{S, t}^{*}, R_{t}^{*}\right\}_{t=0}^{\infty}$, such that (i) given $\left\{W_{U, t}^{*}, W_{S, t}^{*}, R_{t}^{*}\right\}_{t=0}^{\infty}$, the sequences $\left\{C_{t}^{*}, K_{t}^{*}, x_{t}^{*}, \hat{z}_{t}^{*},\right\}_{t=0}^{\infty}$ solve the household 
problem; (ii) factors are paid their marginal products for all $t$; and (iii) markets clear for all $t$.

\subsection{Balanced Growth}

Along a balanced growth path, aggregate physical capital investment, as well as investment in augmenting talent, output, consumption, skilled labor, and unskilled labor, grow at the constant population growth rate $g_{L}$. Factor prices, capital per worker $(k \equiv K / L)$, investment per new skilled worker $(x)$, and the threshold $\hat{z}$ are constant.

Note that the laws of motion for unskilled labor imply that unskilled labor per worker $(u \equiv U / L)$ equals $\int_{0}^{\hat{z}^{*}} z g(z) d z$ along the balanced growth path. Similarly, skilled labor per worker, $(s \equiv S / L)$, equals

$$
s^{*}=\frac{h^{*} \int_{\hat{z}^{*}}^{\bar{z}} z g(z) d z}{1+g_{L}} .
$$

Given the constant return to scale (CRS) properties of the aggregate technology, we can write $Y=L f(k, s, u)$. Hence, along the balanced growth path, equation (7) and competitive factor prices imply

$$
\frac{\partial f\left(k^{*}, s^{*}, u^{*}\right)}{\partial k}=p\left(\frac{1}{\beta}-(1-\delta)\right) .
$$

Similarly, condition (8) and competitive prices imply

$$
\frac{\partial f\left(k^{*}, s^{*}, u^{*}\right)}{\partial u} \hat{z}+x^{*}=\beta \frac{\partial f\left(k^{*}, s^{*}, u^{*}\right)}{\partial s} \hat{z}^{*} B x^{* \phi}
$$

Likewise,

$$
\left(1-G\left(\hat{z}^{*}\right)\right)=\beta \frac{\partial f\left(k^{*}, s^{*}, u^{*}\right)}{\partial s}\left[\int_{\hat{z}}^{\bar{z}} z g(z) d z\right] \phi B x^{* \phi-1}
$$

Hence, equations (15), (16), and (17) can be used to solve for a steady-state equilibrium. They determine the steady-state per worker capital stocks for both types of workers, the threshold value $\hat{z}^{*}$, and the investment in augmenting talent $x^{*}$.

How do changes in TFP and the barrier to capital accumulation affect the division of the labor force between skilled and unskilled workers? We show below that under empirically plausible conditions, economies with lower TFP and higher investment barriers are characterized by a lower fraction of skilled workers. 
Assumption 1 The density $g($.$) is log-concave.$

Proposition 1 Let $\rho \in[0,1)$. Suppose that Assumption 1 holds. Then,

1. There is a unique steady state with $\hat{z}^{*}>0$ and $x^{*}>0$.

2. An increase in TFP, A, (or a reduction in barrier, $p$ ) implies:

- a reduction in $\hat{z}^{*}$, if $\rho \in(0,1)$;

- no effects on $\hat{z}^{*}$, if $\rho=0$; and

(Cobb-Douglas case)

- no effects on $\hat{z}^{*}$ if $\phi \rightarrow 0$.

Proof. See the appendix.

The above proposition is useful later for our analysis and some comments are in order. First, it provides conditions under which a unique steady state exists. This is naturally important for the quantitative analysis that we conduct later. These conditions are sufficient and easily satisfied. Many widely used distributions satisfy the log-concavity requirement; this family includes the uniform, the exponential, the normal, and the gamma distributions. Second, the proposition shows that the relative fraction of skilled workers and investment in augmenting their talent increases with an increase in TFP (or a reduction in the barrier to capital accumulation) when the parameter restrictions are satisfied. It is worth emphasizing here that a host of empirical estimates of the elasticity of substitution between skilled labor and unskilled labor fall within the range required. For the limiting case of a Cobb-Douglas aggregator of skilled and unskilled labor, changes in TFP have no effects on skill segregation. Finally, goods investment in augmenting talent (equation (4)) is essential for any steadystate effects of TFP on skill segregation. In the absence of such investments, changes in TFP or in the barrier to capital accumulation are neutral. 


\section{Parameter Values}

We start by setting the model period equal to four years, a compromise on the time required to become a skilled worker. To calibrate parameter values we use the U.S. as a benchmark. We explain later which aspects of our parameterization change for the cross-country analysis.

Technology We set the share $(\alpha)$ in the aggregate production function to a standard value of 0.33 , based on the findings of Gollin (2002) on labor share across countries. Empirical studies indicate an elasticity of substitution between skilled and unskilled labor of around 1.5 (Katz and Murphy (1992), Heckman, Lochner, and Taber (1998)). Then we set the parameter $\rho$ in the aggregate production technology to $1 / 3$. The depreciation rate is set to $26.6 \%$ (7.4\% annual rate), so the model is consistent with the observed investment-to-output ratio given the empirical magnitude of the capital-to-output ratio. Using NIPA data for the period 1960-2010 and a broad notion of capital, we calculate an average investment-to-output ratio of 0.27 and a related capital-to-output ratio of 0.8 at the four-year frequency (3.2 at the annual frequency). We normalize the TFP level $(A)$ and the efficiency of investments in augmenting talent $(B)$ to 1.0 .

From the technology side, the curvature parameter in the production of skills $(\phi)$ and the share parameter in the production function $(\mu)$ remain to be set. We choose these parameters so that in steady state the model reproduces two empirical targets. The first target is the fraction of unskilled workers in the U.S. from Barro and Lee (2010). This amounts to about $48 \%$ and corresponds to the fraction of the population aged 15 years or older that completed secondary education or less. The second target is expenditure per tertiary student as a fraction of GDP per worker (at PPP values) in the U.S. This fraction was $28.7 \%$ in 2004 and is from the UNESCO 2007 World Education Indicators report.

Preferences and Demographics We choose the discount factor so that the steadystate (four-year) capital-to-output ratio is 0.8 . This implies a discount factor $(\beta)$ equal to 0.869 (0.966 at the yearly frequency). This choice dictates an annual interest rate of about $3.6 \%$. We set the growth rate in population equal to the annual value of $0.9 \%$, calculated using the population figures in the Penn World Tables 7.0. 
PISA Scores and the Distribution of Talent We calibrate the distribution of talent using PISA data. We assume a gamma distribution of PISA scores with parameters $\kappa$ and $\theta$. We choose $\kappa$ and $\theta$ to reproduce the observed U.S. mean and coefficient of variation in the PISA math test score. We assume that the PISA score is mapped into our theoretical notion of talent as $z=\mathrm{PISA}^{\epsilon}$. This amounts to a choice of units for our model.

We choose $\epsilon$, in conjunction with the rest of parameter values, so that in steady state the model reproduces the observed skill premium for males in the United States. From the U.S. Current Population Survey, we calculate the ratio of average earnings per skilled worker to the average earnings per unskilled worker as 1.88 for the period 2001-10. (See Section 8 for a discussion of the notion of skill premium in the context of the model.)

Tables 3 and 4 summarize the resulting parameter values, the empirical targets in our parameterization, and the corresponding model's performance. Several comments are in order. First, our parameterization implies $\phi=0.34, \mu=0.323$, and $\epsilon=0.26$. These parameters are estimated simultaneously and require solving the model to reproduce the data. Second, the model reproduces the data, as Table 4 illustrates. Table 4 also shows that our parametric gamma approximation to the PISA data is good, as it reproduces multiple percentiles of the distribution quite well. Third, our empirical specification for talent is linked to PISA data by the parameter $\epsilon$. Our method for choosing $\epsilon$ is a natural one, given the parsimony of our model and the implications of this choice for a statistic such as the skill premium. Finally, it is worth noting that the gamma density is log-concave if the shape parameter $\kappa$ exceeds 1 , which holds in Table 4 . It can be shown that the implied distribution of talent $(z)$ under our empirical specification is log-concave if $\epsilon<\kappa$. Since we obtain $\epsilon<1<\kappa$, the U.S. distribution of talent is log-concave as well and in line with the assumption in Proposition 1.

To study the implications of our model for the relative importance of TFP in explaining cross-country income differences and labor quality differences, we change some parameters in subsequent sections to match country-specific targets. The country-specific parameters include the gamma distribution parameters, $\kappa$ and $\theta$; the population growth rate, $g_{L} ;$ TFP, $A$; the barrier to capital accumulation, $p$; and the relative efficiency of the goods investment in augmenting talent, $B$. We pick $\kappa, \theta, g_{L}$, and $p$ directly from country-specific data without solving the model and calibrate $A$ and $B$ by solving the model to match country-specific 
targets. Note that $\epsilon$ is not country specific since we have already chosen the units of talent for our model through this parameter. (Under the calibrated value of $\epsilon$ and country-specific values of $\kappa$ and $\theta$, the resulting densities of talent for all countries in the PISA sample are log-concave, as assumed in Proposition 1.)

\section{Model Mechanics}

In this section, we explore the long-run effects of a number of changes in the calibrated parameters of the benchmark economy. In doing so, we highlight the role of the different forces at work to help readers understand our main results in subsequent sections. Specifically, we consider the following empirically motivated departures from the benchmark case. We consider a reduction in the mean talent, an increase in the dispersion of talent, and a reduction in TFP. We first entertain these changes in isolation and then combine all of these changes. The motivation for the specific experiments is straightforward. In Section 2, we documented substantial differences in mean PISA scores across countries and in the correlation between the PISA score and output per worker. In addition, since there is within-country variation in test scores that may be important in the context of our environment, we also assess the effects of changes in dispersion. Finally, the variation in TFP, in conjunction with changes in the distribution of PISA scores, contributes to assessing the relative importance of TFP for output variation and the division of labor across countries.

A Reduction in Mean PISA scores In our first experiment, we consider a reduction in the mean math score to the mean level in the 10th percentile country in the cross-country distribution of mean PISA scores. Results are summarized in Table 5. Intuitively, all else remaining the same, a reduction in the mean score leads to a reduction in mean talent and a reduction in the value of investing in skilled workers (see equations (9) or (17)). Hence, as Table 5 shows, this reduction decreases the augmented talent of skilled workers $(h)$ and increases the threshold $\hat{z}$ across steady states, which in turn implies an increase in the fraction of unskilled workers.

Quantitatively, the effect of the reduction in mean PISA scores on output per worker is not large. Reducing mean scores from the benchmark case to the mean of the 10th percentile country implies a reduction of about $18 \%$. The corresponding decline in output across steady 
states is about $8.1 \%$.

An Increase in Dispersion of PISA Scores Within-country dispersion in PISA scores varies inversely with the level of economic development. In our second experiment, we consider an increase in the coefficient of variation of PISA scores to the level in the 90th percentile country in the cross-country distribution of this variable. That is, in line with the data, we make the distribution of talent more unequal by increasing the coefficient of variation from the benchmark value of 0.19 to 0.23 . Table 5 shows that this change leads to an increase in the fraction of unskilled workers across steady states and an increase in the investments in augmenting the talent of skilled workers. This is intuitive: An increase in dispersion, all else equal, implies an increase in the talent of those at the top tail of the talent distribution (i.e., skilled workers). Quantitatively, as Table 5 shows, the most significant changes are in the fraction of unskilled workers, which increases by about $1 \%$. Given our parameterization, a more unequal distribution of talent results in higher output, but by only about $0.4 \%$.

A Reduction in Total Factor Productivity Reducing the value of TFP leads to the results discussed in Proposition 1. As goods are an input for augmenting the talent of skilled workers and since the elasticity of substitution between skilled labor and unskilled labor is higher than 1 , the reduction in TFP leads to an increase in the threshold $\hat{z}$ and to a decrease in the quality of skilled labor.

Quantitatively, the magnitudes of the effects in Table 5 are substantial. Reducing the value of TFP by $50 \%$ implies an increase in the fraction of unskilled workers of about $11.4 \%$, a decrease in augmented talent of about $36 \%$, and a decrease in output of nearly $74 \%$. As we elaborate later, TFP reductions of these magnitudes are indeed required to account for the output per worker gaps in our sample.

It is important to note that the effects of TFP differences on output in our model are significantly larger than those in the standard growth model. Reducing TFP by $50 \%$ in the standard growth model leads to an output reduction of about $65 \%$ (versus $74 \%$ in our model). The additional amplification effect in our setup stems from the fact that the quality of labor is endogenous. In addition to the standard effects on capital formation, a reduction in TFP leads to a different composition of the labor force (higher fraction of unskilled workers) and 
a lower investment in skilled labor.

Combined Effects of All Changes The last row in Table 5 shows the combined effects of all changes simultaneously. As a poor country in our sample is similar to this hypothetical scenario, the combined effects are illustrative for the quantitative implications of our model. The table shows that when all changes are combined, the fraction of unskilled workers increases by $13 \%$, the augmented talent decreases by more than $33 \%$, and output decreases by about $76 \%$. The table also demonstrates that the changes in TFP capture the bulk of the effects on output and the composition of the labor force.

\section{$6 \quad$ Findings}

In our model, country-specific parameters include the population growth rate, the barrier to capital accumulation, the talent distribution, TFP, and the efficiency of goods investment in augmenting talent $(B)$. In addition, our analysis explicitly takes into account the international heterogeneity in enrollment rates as documented earlier.

A required input to the model is the talent of each 15-year-old in each country, but in the data we observe the PISA score for only those 15-year-olds enrolled in school. Therefore, we need to assign a measure of talent to the 15-year-olds not enrolled in school. Let $\gamma \in(0,1)$ denote the fraction of 15 -year-olds enrolled in school. We assign to the rest (fraction $1-\gamma$ ) a common set of talent, $z_{\min }$. This procedure implies that the stationary values of unskilled and skilled labor per worker obey, respectively,

$$
\begin{gathered}
u^{*}=(1-\gamma) z_{\min }+\gamma \int_{z_{\min }}^{\hat{z}^{*}} z g(z) d z, \text { and } \\
s^{*}=\frac{\gamma}{1+g_{L}} h^{*} \int_{\hat{z}^{*}}^{\infty} z g(z) d z .
\end{gathered}
$$

For each country, the fraction $\gamma$ is reported in the PISA data. We set $z_{\text {min }}$ for each country based on the 10th percentile of the PISA math test score for that country.

We use the observed relative price of investment as a measurement of the barrier to capital accumulation, as in Restuccia and Urrutia (2001) and others. The values of the 
country-specific population growth rates and relative price of investment are those reported in the Penn World Tables 7.0.

Three Experiments We present our results in three groups, organized according to the sources of exogenous variation across countries. For the first group of results, we assign to each country its population growth rate and its distribution of talent parameterized from PISA data, with adjustments of enrollment as explained above, and then compute the steadystate equilibrium for each country. The cross-country differences in population growth rates have negligible effects on our findings. Hence, we refer below to the first group as Variation in PISA Scores. Operationally, this implies that the parameters $\theta$ and $\kappa$ are specific to each country. The results and their relation to data are reported in Table 6; we present our findings according to the observed distribution of output per worker — for example, the poorest $10 \%$ of countries versus the richest $10 \%$ of countries.

For the second group of results, we add to the first experiment variation in the barrier to capital accumulation and TFP across countries. We compute the relative TFP levels such that the output per worker in the model and in the data are the same. Table 7 illustrates the consequences of combining all of these variations. Variations in the relative price of investment are of second-order importance once we take into account cross-country differences in TFP. Hence, we refer to the second group as Variation in TFP and PISA Scores.

For our third group of results, we refine the second experiment by adding a variation in the technological parameter $B$ across countries. We now force the model to reproduce both the levels of output per worker and the fraction of unskilled workers. Specifically, we allow $B$ to be country specific so that in conjunction with variations in TFP and PISA scores, the model can jointly reproduce output per worker and the division of labor force for each country in our sample. We refer to this group of results as Matching the Division of Labor. Table 8 presents the findings.

In these and subsequent experiments, we refer to labor quality $(l)$ as the per worker labor aggregate of unskilled labor and skilled labor in the CES technology. That is,

$$
l=\left[\mu u^{\rho}+(1-\mu) s^{\rho}\right]^{1 / \rho},
$$


where $u$ is the the stock unskilled labor per worker, $(U / L)$, and $s$ is the stock of skilled labor per worker, $(S / L)$. For ease of exposition, we refer below to the bottom $10 \%$ of countries in terms of output per worker as "poor" and to the top $10 \%$ of countries as "rich."

\subsection{Variation in PISA Scores}

Our results indicate that adding only the variation in PISA scores leads to a lower investment in skilled workers and a higher fraction of unskilled workers in poorer countries. In turn, these changes lead to lower aggregate capital in poorer economies and, given the effects on labor quality, result in lower output.

Quantitatively, the variation in the PISA scores implies that augmented talent $(h)$ in the poor countries is about $96 \%$ of that in the rich countries (see Table 6). Similarly, the fraction of unskilled workers in the poor countries is about $3 \%$ higher. As a result, output per worker is about $90 \%$ in the poor countries relative to the rich countries.

As Table 6 demonstrates, the model generates less than $20 \%$ of the gap in the fraction of unskilled workers between the poor and the rich countries. In terms of output per worker, the productivity in the rich countries is about $11 \%$ higher than that in the poor countries; in the data, the gap is a factor of more than 8. As in the previous literature, there is an ample role for TFP differences across countries to account for the observed income differences.

\subsection{Variation in TFP and PISA Scores}

When we add TFP variation and the observed variation in the barrier to capital accumulation to the previous sources of exogenous variation across countries, we find that our framework can now account for a substantial fraction of the differences in the division of labor across countries (see Table 7). With TFP levels that match the output per worker levels exactly, the model captures more than $100 \%$ of the differences in the fraction of unskilled workers between the poor and the rich countries. Thus, with TFP differences and their interplay with the PISA score differences, the model can be helpful in understanding the cross-country differences in the division of labor.

Table 7 illustrates the size of TFP differences needed to account for the output per worker differences. TFP in the poor countries is about $37 \%$ of that in the rich countries. Not surprisingly, augmented talent is now substantially lower in the poor countries (only 
$49 \%$ relative to the rich countries) since TFP has an indirect effect on the division of labor and the investment in skilled workers. These changes in quality and division of labor, in conjunction and in response to lower levels in talent, result in smaller differences in TFP than those from standard analyses. We elaborate on this issue in the next section.

\subsection{Matching the Division of Labor}

We now force the model to reproduce exactly both the level of output per worker and the fraction of unskilled workers. We do so by allowing both TFP and the relative investment efficiency parameter $B$ to be country specific, along with the other sources of variation considered earlier.

Table 8 shows the results of this exact matching. As the table shows, differences in TFP are now smaller relative to those in Table 7. The model requires lower levels of efficiency $B$ in poorer countries than in rich countries. These country-specific $B$ levels lead to larger differences between rich and poor countries in the values of labor quality. These larger crosscountry differences in labor quality, in turn, lead to smaller TFP differences. In Table 8, TFP in the poor countries is about $41 \%$ of that in the rich countries, whereas in Table 7 the corresponding number is only $37 \%$, where $B$ was set equal to 1 for all countries and the model was not forced to reproduce the cross-country variation in the division of labor.

Tables 6, 7, and 8 clearly show the progression of the magnitude of labor quality differences across experiments. The first experiment (Variation in PISA Scores) indicates that the labor quality in the poor countries is about $89 \%$ of the labor quality in the rich countries. When variation in TFP is added in the second experiment, the corresponding figure for labor quality is about 55\%; also matching the division of labor by skill in the third experiment leads to a labor quality figure of $45 \%$. In our model, (measured) differences in achievement at age 15 (i.e., PISA scores) generate only about $10 \%$ of the rich-to-poor ratio of labor quality; the remaining implied differences in labor quality are due to the combined effects of differences in TFP, the barrier to capital accumulation, the efficiency of investments in skilled workers, and their interplay with the achievement scores.

In summary, matching the division of labor in each country leads to smaller TFP differences between rich and poor countries. Quantitatively, however, the bulk of the resulting TFP differences are already captured when we force the model to reproduce output per 
worker differences across countries. Matching the division of labor contributes only modestly to reducing the implied TFP gaps across countries.

\section{Comparison with Related Exercises}

In this section, we i) compare the predictions of our model with those resulting from the standard one-sector growth model and ii) provide summary statistics in different cases through corresponding elasticities of output per worker with respect to TFP. We also connect our findings with those in Erosa et al. (2010).

Recall that in our model, output per worker $(y)$ can be written as

$$
y=A k^{\alpha} l^{1-\alpha},
$$

where $k$ is capital per worker and $l$ is labor quality. This provides the basis for a comparison with the standard one-sector model. The central difference between our model and the standard one is in the notion of labor quality: In the latter, $l$ is measured using years of schooling and Mincerian returns.

To compute $l$ in the one-sector model, we assume, as in Hall and Jones (1999), Caselli (2005), and others, that

$$
l=\exp \psi(s)
$$

where $\psi$ is a function of years of schooling $(s)$ and is determined by rates of return that vary with average years of schooling (as in Psacharopoulos (2004)). Specifically, we set $\psi(s)=0.134 s$ for $s \in[0,4], \psi(s)=0.134 \times 4+0.101(s-4)$ for $s \in(4,8]$, and $\psi(s)=$ $0.134 \times 4+0.101 \times 4+0.068 \times(s-8)$ for $s>8$. We use the average years of schooling in each country as reported by Barro and Lee (2010). All other parameters in the model are set as in Section 4. We input the relative prices of investment from Penn World Tables 7.0 into the one-sector growth model and find the levels of TFP that reproduce the observed relative levels of output per worker.

The one-sector growth model results are presented in Table 9, where we also present for comparison the corresponding results from our model when we match the division of labor and when we do not. As the table indicates, the implied differences in TFP are much larger 


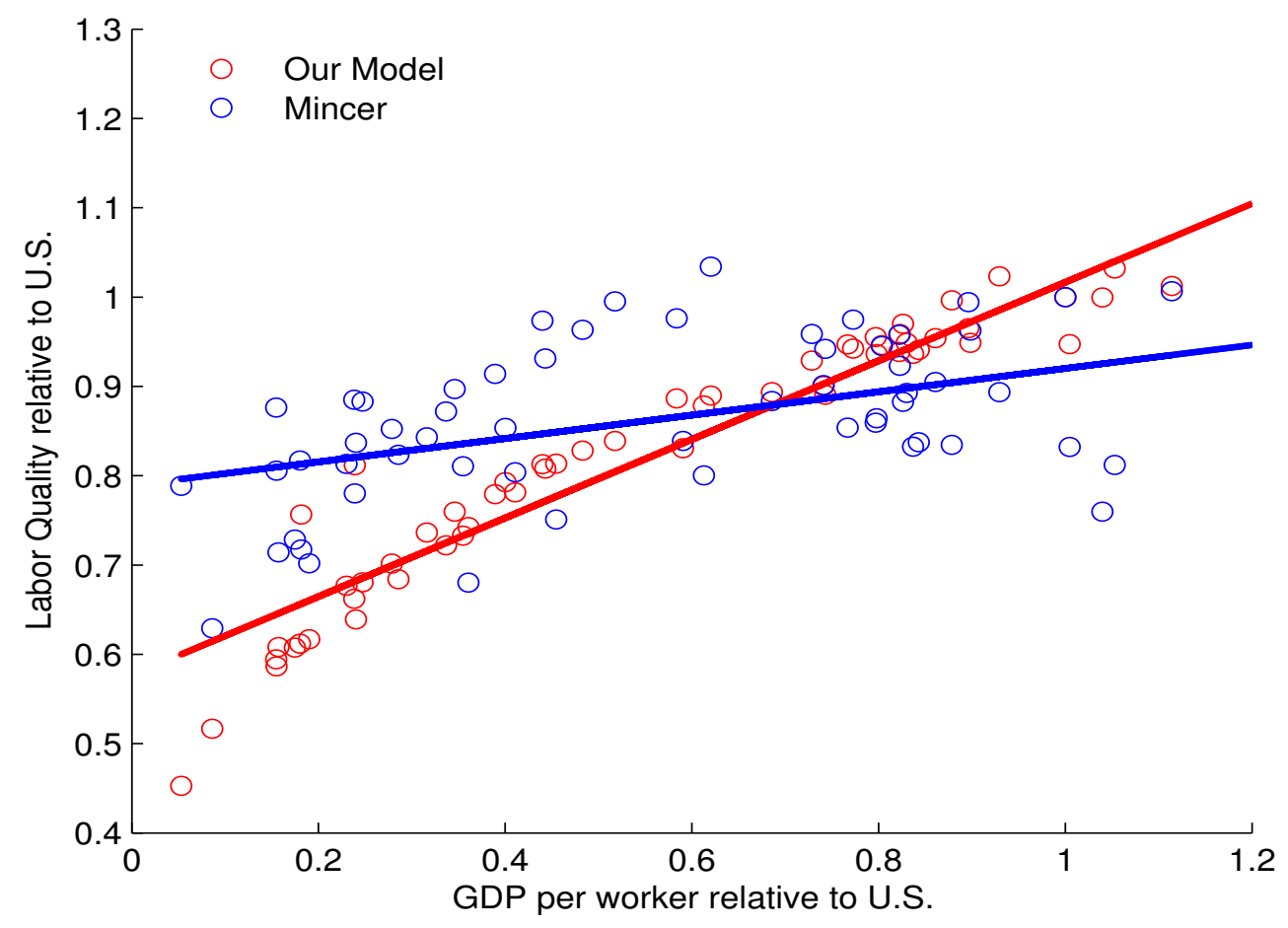

Figure 4: Labor quality and GDP per worker: model versus Mincerian measure.

in the one-sector growth model with labor quality measured by Mincerian returns. In the one-sector growth model, TFP in the poor countries is about $28 \%$ of TFP in the rich countries (Panel A). In contrast, the ratio in our model is $41 \%$ when we match the division of labor by skill (Panel C). Clearly, the larger TFP differences are due to the differences in the value of labor quality in the two cases. In the one-sector growth model, labor quality is about $86 \%$ in the poor countries relative to the rich countries, whereas our model generates a difference of $45 \%$. Figure 4 illustrates how labor quality varies with development by comparing labor quality in our model with labor quality under the conventional Mincerian measure. As the figure shows, the slope of the predicted relationship is much larger in our model than under the conventional notion of labor quality.

PISA as Labor Quality Suppose that instead of using our theory of labor quality, we simply use the mean levels of PISA scores as a measure of each country's labor quality. That is, there is no division of workers by skill and no investments in the quality of skilled labor. How would this approach affect relative TFP? 
To answer this question, we assign the mean levels of PISA scores as each country's labor quality and then proceed to find the TFP level in each country that reproduces the empirical level of output per worker. Our results indicate that TFP in the poor countries is about $31 \%$ relative to that of the rich countries (it is $28 \%$ in the one-sector growth model exercise). Hence, the resulting TFP differences are substantially larger than in the benchmark scenarios and similar to those in the one-sector model with labor quality measured by Mincerian returns.

In summary, TFP in our model has not only a direct effect on output, but also an additional, indirect effect through the division of labor into skilled and unskilled workers and the investment in skilled workers. Stated differently, labor quality in our setup is a function of TFP. This feature is reflected in our elasticity of output per worker with respect to TFP, which is larger than the one obtained with the standard growth model. One implication of our findings is that the mechanism in our model reduces nontrivially the importance of TFP in explaining cross-country income differences. Nonetheless, our findings still attribute a central role to TFP differences. As Table 9 shows, TFP differences between the rich and poor countries in our sample exceed a factor of two.

\subsection{Elasticities}

A convenient way to summarize our findings is to calculate the elasticity of output per worker across countries with respect to TFP in different experiments. Such calculation provides a snapshot of our findings that can readily be compared with findings from other papers. Table 10 provides the resulting elasticities in our experiments. As is well known, the onesector growth model without labor quality adjustments implies an elasticity of 1.5 (equal to the inverse of the labor share). When labor quality is measured by Mincerian returns, we estimate an elasticity of around 1.7 in the one-sector growth model, a higher value than 1.5 since labor quality is correlated with output per worker. If instead we define labor quality as simply the mean PISA score in each country, the elasticity is 1.8. Different specifications of our model imply elasticities that are larger, but within a narrow range. Our model implies an elasticity of about 2.1 for Variation in TFP and PISA Scores case and of about 2.2 for Matching the Division of Labor case. These estimates are of the same order of magnitude as the elasticities obtained by Erosa et al. (2010). 


\subsection{Relation to Erosa, Koreshkova, and Restuccia (2010)}

Since our model delivers TFP elasticities similar to those in Erosa et al. (2010), we provide an interpretation of their work in relation to ours. Erosa et al. (2010) present a model with incomplete markets, where dynastic households invest in the skills (human capital) of new dynasty members. In their model, the heterogeneity in learning ability, taste for schooling of the young, and human capital shocks (market luck), combined with human capital investments requiring time and goods, determine the distribution of human capital. Increases in TFP lead to an increase in the mean value of human capital as the human capital accumulation requires both time and market goods. When their model is disciplined by a host of microeconomic evidence, the authors find TFP elasticity of output per worker around 2 .

Our model provides a simple way to integrate a novel piece of data (PISA scores) into a growth model. The innovation is that these data provide direct evidence of a key component of the skill bundle of individuals — skills embodied in individuals by the end of compulsory schooling - that positively covaries with output per worker. Upon entering the labor force, individuals are divided into unskilled and skilled, and there are time and goods investments - as in Erosa et al. (2010). As TFP increases, labor quality increases as a result of i) changes in the division of the labor force and ii) goods investments. As our model is also disciplined by evidence - division of the labor force, skill premia, and expenditures in tertiary education - the resulting distribution of human capital cannot differ much from that in Erosa et al. (2010). Hence, it is not surprising that the overall response of output to TFP changes is quite similar to that in Erosa et al. (2010).

\section{Skill Premia}

In this section, we discuss the implications of our model for the earnings of skilled workers relative to those of unskilled workers, or skill premia. This is important as it reflects on the quantitative implications of the economic mechanisms in our paper for data that we do not explicitly target.

Our measures of skill premia are from Fernandez, Guner, and Knowles (2005). The data used by these authors are calculated directly from national surveys from 1990 to 1997. Their 


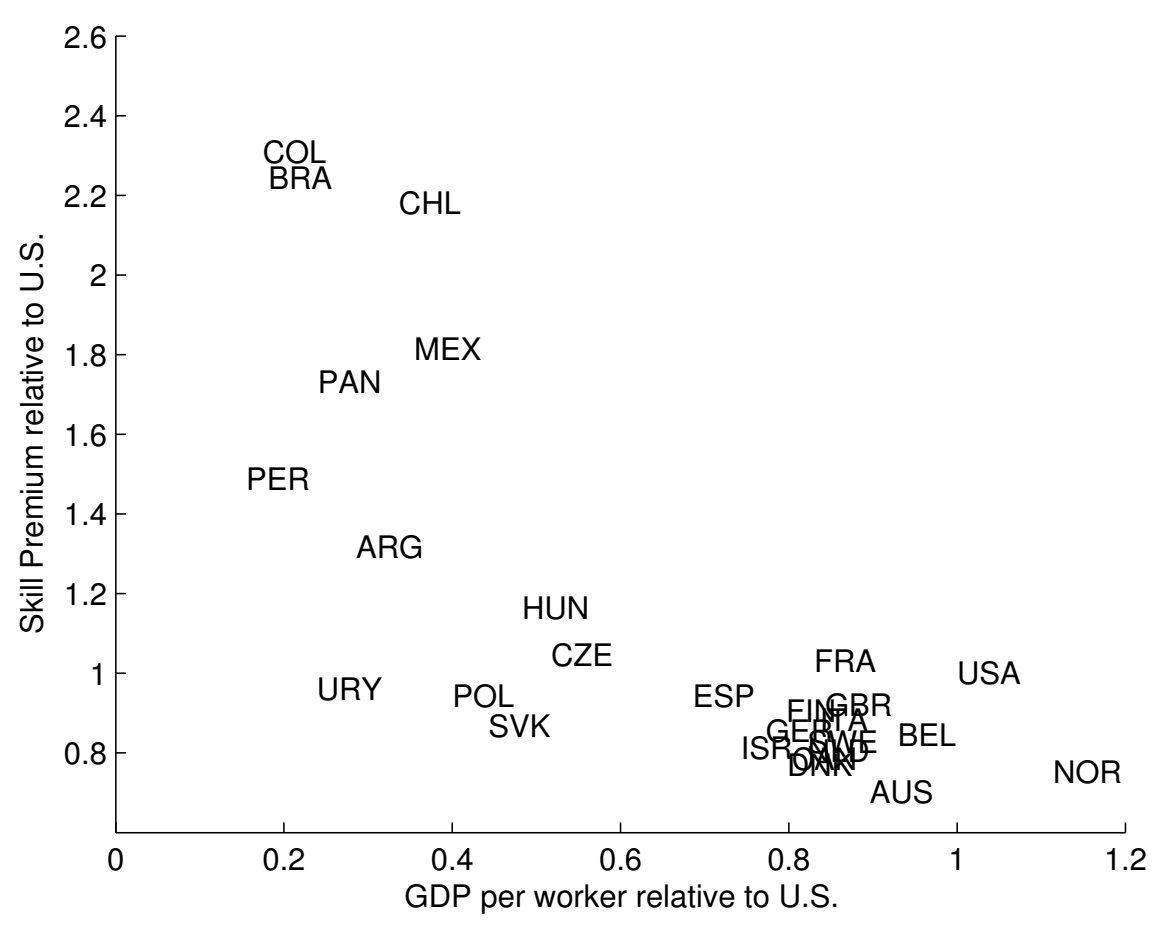

Figure 5: Skill premium and GDP per worker.

sample is smaller (34 countries) than ours (59 countries). The countries included are Argentina, Australia, Belgium, Bolivia, Brazil, Canada, Chile, Colombia, Costa Rica, Czech Republic, Denmark, Ecuador, Finland, France, Germany, Hungary, Israel, Italy, Luxembourg, Mexico, the Netherlands, Norway, Panama, Paraguay, Peru, Poland, Slovakia, Spain, Sweden, Taiwan, the United Kingdom, the United States, Uruguay, and Venezuela. This is a subset of the set of countries in our benchmark. The skill premium is defined as the ratio of earnings (labor income) per worker for skilled male workers to those of the unskilled ones. ${ }^{3}$ A skilled worker is an individual who has more years of education than those required to complete secondary school. Therefore, this definition is consistent with our data on educational attaintment. Figure 5 plots the skill premia (relative to the U.S. value) against output per worker for each country (relative to the U.S. value). As the figure shows, there is a negative correlation between these two variables, with a correlation coefficient of -0.75 . Table 11 indicates that the skill premium in the poorest $10 \%$ of countries is about 2.4 times the skill premium in the richest $10 \%$.

\footnotetext{
${ }^{3}$ In their sample, workers are husbands between 36 and 45 years of age.
} 
We now construct a skill premium within our model that is consistent with the data in Fernandez et al. (2005). Recall that earnings of an unskilled worker are given by $W_{U}^{*} z$, whereas the earnings of a skilled worker are given by $W_{S}^{*} z h^{*}$. Then, the skill premium (SP), defined as the ratio of per worker earnings of skilled workers to per worker earnings of unskilled workers, is given by

$$
S P=\frac{\left(W_{S}^{*} h^{*} \int_{\hat{z}^{*}}^{\bar{z}} z g(z) d z\right) /\left(1-G\left(\hat{z}^{*}\right)\right)}{\left(W_{U}^{*} \int_{0}^{\hat{z}^{*}} z g(z) d z\right) / G\left(\hat{z}^{*}\right)} .
$$

We can rewrite the above as an expression that involves relative wages, augmented talent $(h)$, and conditional expectations of talent:

$$
S P=\left(\frac{W_{S}^{*}}{W_{U}^{*}}\right) h^{*}\left(\frac{E\left(z \mid z \geq \hat{z}^{*}\right)}{E\left(z \mid z<\hat{z}^{*}\right)}\right) .
$$

We note that the skill premium in the model that is comparable with the measurement in Fernandez, Guner, and Knowles (2005) is not just relative wages. Hence, changes in the division of the labor force by skill will generate movements in all of the components above. Note that an increase in the fraction of unskilled workers (i.e., an increase in $\hat{z}^{*}$ ) reduces the conditional expectations of talent but increases relative wages. Hence, changes in skill premia implied by the model are the result of countervailing forces.

Findings In line with our benchmark analysis, we conduct experiments using data from only the restricted sample of countries (34 instead of 59). The experiments are conceptually the same as in the benchmark exercises. First, we consider Variation in TFP and PISA Scores. Our second experiment is Matching the Division of Labor case; that is, we add country-specific variation in investment efficiency $(B)$ to variations in TFP and PISA scores.

Table 11 shows the performance of the model for the skill premium and its components. When we consider the Variation in TFP and PISA Scores case in our restricted sample, the model does not perform well in terms of the observed differences in the division of labor. This performance is worse than our benchmark. The model generates about half of the variation in the fraction of unskilled workers between the poor and rich countries relative to the data. In terms of skill premia, the model does not generate significant differences across countries. In the data, the skill premium in the poor countries is about $144 \%$ higher than the premium in the rich countries; in the model it is just $2.7 \%$. 
When the model is forced to reproduce the division of labor by skill along with output per worker, it generates a higher skill premium in the poor countries: $115 \%$ higher than that in the rich countries. We conclude that forcing the model to reproduce the division of labor by skill is important in accounting for skill premia. As discussed earlier, accounting for the observed division of labor is not critical in quantifying the importance of TFP for income differences in our model. Nevertheless, reproducing the division of labor appears to be key in accounting for variation in skill premia.

\section{Discussion}

We now attempt to put our findings in perspective. To this end, we investigate the importance of the distribution of PISA scores and the components of labor quality for our results. For the latter, we investigate the role of (i) investments in skilled workers as an amplification mechanism, (ii) the mapping from PISA scores to talent, and (iii) the elasticity of substitution between skilled labor and unskilled labor.

\subsection{How Important Are Differences in Talent?}

A natural way to assess the impact of differences in talent across countries is to conduct a counterfactual exercise in which we assign to the poorest country in the sample the PISA distribution of the United States without altering its TFP level.

The poorest country in our sample is the Kyrgyz Republic, which incidentally has the lowest mean value of PISA (math) in the sample. This country has an output per worker of $5.6 \%$ of the United States (the U.S. is richer by a factor of nearly 17). Our model implies that assigning to the Kyrgyz Republic the PISA distribution of the U.S., retaining the Kyrgyz Republic's parameters and TFP as calibrated in Section 6.2, would lead to a level of output per worker about $14.2 \%$ higher than in the data - a minor change given the large observed income disparity. Since the capital-to-output ratio is unchanged across steady states, the experiment implies an increase in the labor quality of the Kyrgyz Republic that is also about $14.2 \%$, which stems from an increase in both the unskilled labor and skilled labor inputs. The fraction of unskilled workers drops by about $2 \%$. If instead we use the TFP level and the investment efficiency $B$ found in Section 6.3 for the Kyrgyz Republic, the corresponding

level of output per worker would be $13.5 \%$ higher than in the data, with a drop in the 
fraction of unskilled workers of about $0.8 \%$. Thus, adding differences in the efficiency of skill investments does not change the main outcome of the exercise.

It is worthwhile to comment on these findings in relation to those from reduced-form studies on the effect of cognitive skills — measured by test scores — on long-run growth rates. These studies attribute substantial effects to cross-country variation in cognitive skills, Hanushek and Woessmann (2012), for instance, find that one standard-deviation increase in a measure of cognitive skills increases the output growth over 40 years by about 1.3 percentage points on an annual basis. ${ }^{4}$ Since the difference between the mean value of the PISA score in the Kyrgyz Republic and the United States is about 3 standard deviations, these results imply a hypothetical increase in output per worker for the Kyrgyz Republic of a factor of nearly 5 over 40 years.

Several factors can account for the differences between our results and those found in the reduced-form literature. We consider exclusively differences in PISA scores across countries, whereas Hanushek and coauthors consider variation in a constructed index of test scores. More importantly, we vary PISA scores in isolation; PISA scores and a broad notion of TFP are arguably correlated in the data as our analysis shows. From this perspective, it is perhaps not surprising that movements in cognitive skills are strongly associated with long-run growth rates.

These findings also shed light on the potential importance of early-childhood investments on economic development, even though our model is not designed to capture such investments. As noted earlier, our model implies that in the long run, endowing the Kyrgyz Republic with the distribution of PISA scores of the United States results in at most $14.2 \%$ increase in output. This effect is of second-order importance in our model when compared to the output effect associated with changes in TFP: Endowing the Kyrgyz Republic with the TFP level of the U.S. results in a 10-fold increase in output. In fact, it would take less than a $10 \%$ increase in TFP of the Kyrgyz Republic to deliver a long-run increase in output of $14.2 \%$ delivered by the PISA scores!

Overall, this exercise illustrates a central implication of the findings of our paper. While differences in PISA scores and the endogeneity of labor quality in our model reduce nontrivially the TFP differences required to reproduce income differences across countries, TFP

\footnotetext{
${ }^{4}$ These results pertain to the case when East Asian countries are excluded; see Table 2 in Hanushek and Woessmann (2012). When included, the effects are larger and about 2 percentage points on an annual basis.
} 
differences are still the dominant force in accounting for income differences.

\subsection{How Important Are the Amplification Effects of Investments in Skilled Workers?}

To what extent are the TFP differences amplified by goods investment in augmenting talent? To answer this question, we first set the parameter $\phi$ to 0 , eliminating any incentive to invest in skilled workers. We then find the relative levels of TFP that reproduce the empirical levels of output per worker; these results are shown in Table 12. TFP differences between poor and rich countries become significantly larger. With no investments in skilled workers, TFP in the poor countries is just $27 \%$ of TFP in the rich countries. The corresponding elasticity of output with respect to TFP is around 1.65, quite similar to the elasticity observed under the Mincerian notion of labor quality.

We then repeat this exercise for a wide range of values of $\phi$. Figure 6 shows the results for the TFP elasticity of output per worker. Raising the value of $\phi$ from 0 to the benchmark value of 0.34 leads to a proximate linear increase of the elasticity from 1.65 to 2.1. Thereafter, the TFP elasticity increases more rapidly. Doubling the benchmark value of $\phi$ leads to a TFP elasticity in excess of 3 . A high value of $\phi$ at 0.9 implies an elasticity of more than 4 .

We conclude from this exercise that investments in skilled workers are of first-order importance. Without them, the TFP differences and the resulting TFP elasticity become quite similar to those from the one-sector growth model. Moreover, values of the curvature parameter $\phi$ beyond those supported by evidence can result in substantially smaller TFP differences between poor and rich countries than those found in our benchmark exercises.

\subsection{What Is the Role of Mapping PISA Scores to Talent?}

The reader should recall that we transform PISA test scores into our notion of talent by the parameter $\epsilon$ :

$$
z=P I S A^{\epsilon}
$$

We note that by choosing $\epsilon$ alongside other parameters, our benchmark model is consistent with the data on skill premia for our measure of skilled and unskilled workers. That is, in our benchmark parameterization, the model generates the skill premium observed in 


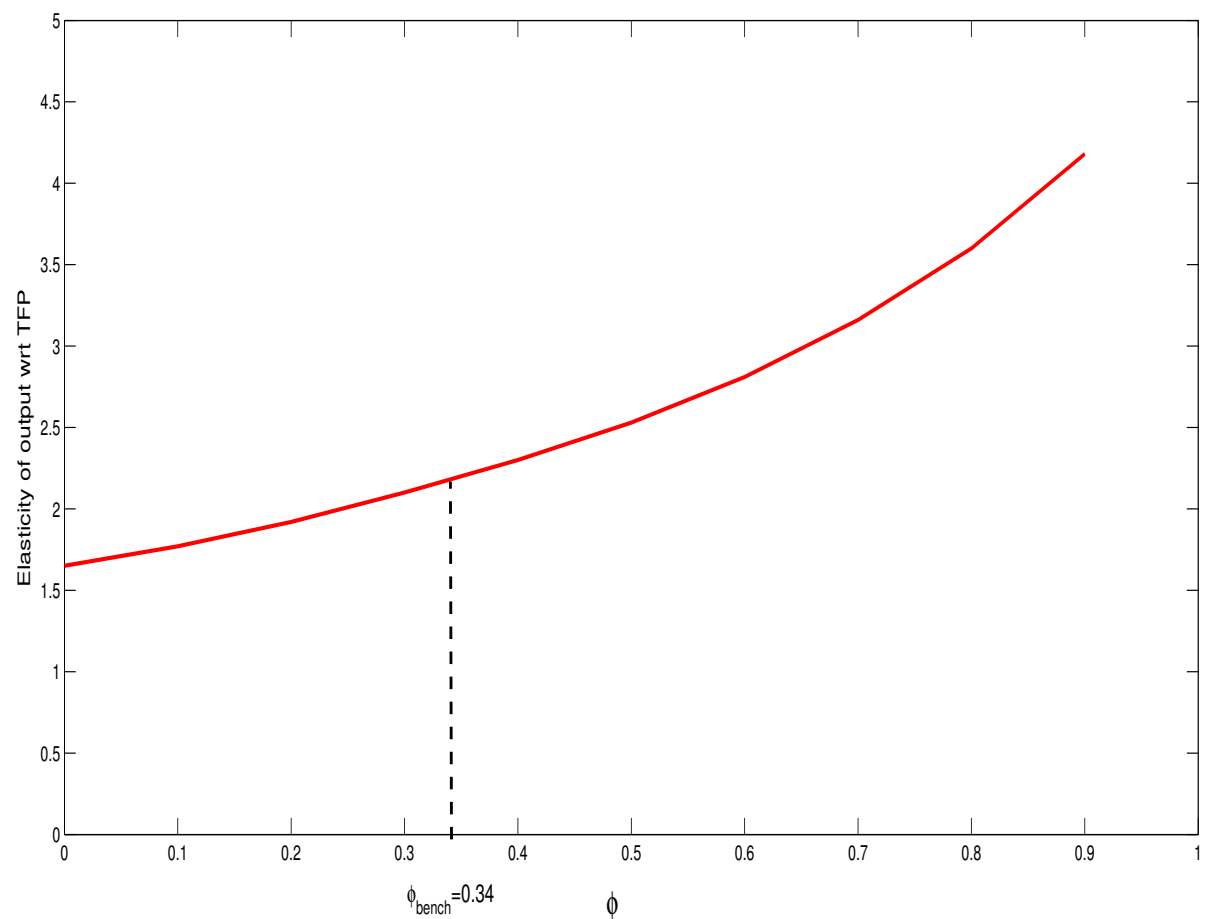

Figure 6: TFP elasticity of $Y / L$ as a function of $\phi$ 
the data (1.88) for the U.S. This is a natural statistic to focus on given the emphasis on the division of a cohort of workers in our model between skilled and unskilled. In this sense, it is a choice of units; without the adjustment by the parameter $\epsilon$, our model generates a counterfactual skill premium, as seen below.

To further understand the implications of the adjustment of PISA units, we consider the quantitative implications of our model without such an adjustment. That is, we set $\epsilon=1$ and recalibrate the other parameters to reproduce all facts except the skill premium. The model then implies a nontrivially higher skill premium of about 2.36, 25\% higher relative to the data. We then consider the consequences for the cross-country development facts, focusing on the Variation in TFP and PISA Scores case as described previously. Our findings are displayed in Table 12. The differences in labor quality between poor and rich countries are larger than in our benchmark. We find a TFP elasticity of output per worker of about 2.6. This is higher than the value of 2.1 in our benchmark model. TFP differences between poor and rich countries are smaller under $\epsilon=1$ than in the benchmark parameterization that reproduces the skill premium. ${ }^{5}$

These findings are not surprising. All else equal, a value of $\epsilon=1$ increases the earnings of skilled workers relative to unskilled workers, which in turn increases the incentives to augment skills. As a result, labor quality varies more with TFP, and the corresponding TFP elasticity of output per worker is larger than that in our benchmark parameterization. Altogether, equating PISA scores to talent leads to a counterfactually high skill premium in the benchmark economy and provides an upper bound on the response of output per worker to variation in TFP.

\subsection{What Is the Role of the Elasticity of Substitution?}

Recently, authors such as Gancia, Mueller, and Zilibotti (2011) and others have argued that the elasticity of substitution between skilled labor and unskilled labor is higher than the conventional value we use. They estimate elasticities in the range of 1.4 to 2.5. What is the quantitative effect on our findings if we assume a high value for this elasticity? To answer the question, we set the elasticity to 2.5 , the highest value in the range above, which corresponds

\footnotetext{
${ }^{5}$ It is worth noting than under our benchmark parameterization, the model is broadly consistent with the available evidence on the relationship between PISA scores and individual earnings. See the online appendix for details.
} 
to a value of $\rho=0.6$ in our model. We recalibrate the model under this assumption and compute the relative levels of TFP that reproduce the empirical levels of output per worker; these results are shown in Table 12. TFP differences are similar to those in the benchmark model. As a result, the elasticity of output with respect to TFP is now about 2.2; it is 2.1 in the benchmark model. It is clear from these results that our main findings do not depend critically on the value of the elasticity of substitution.

\section{Concluding Remarks}

We developed a parsimonious model of the division of labor between skilled and unskilled workers and investments in skilled workers. We used the model and PISA scores to draw inferences on labor quality differences across countries and the relative importance of TFP in economic development.

A central finding of our paper is that labor quality differences between the richest and the poorest countries in our sample are roughly twice as large as those in conventional (Mincerian) notions of labor quality. As a result, the TFP differences are smaller than in the standard growth model. Stated differently, output reacts more strongly to TFP changes in our setup than in the standard growth model, as labor quality is endogenous and responds to variations in PISA scores and TFP. These findings are robust to uncertainty in the magnitude of the elasticity of substitution between skilled and unskilled workers and depend critically on the importance of investments in the augmenting the talent of skilled workers.

We conclude with two comments. First, it is noteworthy that the TFP elasticity of output per worker in our model is the same order of magnitude of recent estimates from Erosa et al. (2010) (about 2). This is important as our result is derived from a different and more parsimonious model, using different calibration targets and direct evidence on the skills embodied in individuals by the end of compulsory schooling. These findings reduce the uncertainty on the role of TFP and labor quality in economic development.

Second, we have taken the variation in talent - via PISA scores - as an exogenous driving force. A concern here might be that PISA achievement scores are themselves endogenous and a function of TFP. If so, wouldn't the TFP differences across countries then be smaller and, as a result, the TFP elasticity of output per worker be larger? Our view is that a deeper model of achievement at the end of compulsory education, and its connection with TFP, should 
be consistent with the observed PISA scores and the resources spent on tertiary education. Our analysis is consistent with these observations. What is needed is a quantitative theory of the observed PISA scores. 


\section{References}

Barro, R. J., \& Lee, J.-W. (2010). A New Data Set of Educational Attainment in the World, 19502010. Nber working paper no. 15902.

Bhathacharya, D., Guner, N., \& Ventura, G. (2013). Distortions, Endogenous Managerial Skills and Productivity Differences. Review of Economic Dynamics, 16, 11-25.

Caselli, F. (2005). Accounting for Cross-Country Income Differences. In Aghion, P., \& Durlauf, S. (Eds.), Handbook of Economic Growth, Vol. 1, chap. 9, pp. 679-741. Elsevier.

Cordoba, J. C., \& Ripoll, M. (2013). What Explains Schooling Differences Across Countries?. Journal of Monetary Economics, 60, 184-202.

Erosa, A., Koreshkova, T., \& Restuccia, D. (2010). How Important is Human Capital: A Quantitative Theory Assessment of World Income Inequality. Review of Economic Studies, 77, 1421-1449.

Fernandez, R., Guner, N., \& Knowles, J. (2005). Love and Money: A Theoretical and Empirical Analysis of Household Sorting and Inequality. Quarterly Journal of Economics, $120(1), 273-344$.

Gancia, G., Mueller, A., \& Zilibotti, F. (2011). Structural Development Accounting. manuscript.

Gollin, D. (2002). Getting Income Shares Right. Journal of Political Economy, 110(2), 458-474.

Hall, R., \& Jones, C. (1999). Why Do Some Countries Produce So Much More Output per Worker than Others?. The Quarterly Journal of Economics, 114, 83-16.

Hanushek, E., \& Kimko, D. (2000). Schooling, labor force quality, and the growth of nations. American Economic Review, $90(5), 1184-1208$.

Hanushek, E., \& Woessmann, L. (2008). The Role of Cognitive Skills in Economic Development. Journal of Economic Literature, 46(3), 607-668. 
Hanushek, E., \& Woessmann, L. (2012). Do Better Schools Lead to More Growth? Cognitive Skills, Economic Outcomes, and Causation. Journal of Economic Growth, 17, 267-321.

Heckman, J., Lochner, L., \& Taber, C. (1998). Explaining Rising Wage Inequality: Explanations With A Dynamic General Equilibrium Model of Labor Earnings With Heterogeneous Agents. Review of Economic Dynamics, 1(1), 1-58.

Hendricks, L. (2002). How Important is Human Capital for Development? Evidence from Immigrant Earnings. American Economic Review, 92(1), 198-219.

Katz, L. F., \& Murphy, K. M. (1992). Changes in Relative Wages, 1963-1987: Supply and Demand Factors. The Quarterly Journal of Economics, 107(1), 35-78.

Klenow, P., \& Rodriguez-Clare, A. (1997). The Neoclassical Revival in Growth Economics: Has It Gone Too Far? In Bernanke, B., \& Rotemberg, J. (Eds.), NBER Macro Annual. MIT Press.

Manuelli, R., \& Seshadri, A. (2010). Human Capital and the Wealth of Nations. manuscript. McGrattan, E., \& Schmitz, J. (2000). Explaining Cross-Country Income Differences. In Taylor, J., \& Woodford, M. (Eds.), Handbook of Macroeconomics, chap. 3. Elsevier.

Parente, S., \& Prescott, E. (2000). Barriers to Riches. Cambridge: MIT Press.

Prescott, E. (1998). Needed: A Theory of Total Factor Productivity. International Economic Review, 39(3), 525-551.

Psacharopoulos, G. (2004). Returns to Investment to Education: A Global Update. World Development, 22, 1325-1343.

Restuccia, D. (2001). Barriers to Capital Accumulation in a Model of Technology Adoption and Schooling. manuscript.

Restuccia, D., \& Urrutia, C. (2001). Relative Prices and Investment Rates. Journal of Monetary Economics, 47(1), 93-121.

Schoellman, T. (2011). Education Quality and Development Accounting. Review of Economic Studies, 79, 388-417. 


\section{A Appendix}

\section{Proof of Proposition 1}

We start by defining the marginal products for our specification of the production technology. Output per worker is given by

$$
y=F(K, U, S ; A) / L=A k^{\alpha} l^{1-\alpha}
$$

with $l \equiv\left[\mu u^{\rho}+(1-\mu) s^{\rho}\right]^{1 / \rho}$. Hence, the marginal products of capital (MPK), skilled labor (MPS), and unskilled labor (MPU) are, respectively:

$$
\begin{gathered}
M P K=A \alpha \tilde{k}^{\alpha-1}, \\
M P S=A(1-\alpha) \tilde{k}^{\alpha}\left[\mu+(1-\mu) \tilde{s}^{\rho}\right]^{\frac{1-\rho}{\rho}} \tilde{s}^{\rho-1}(1-\mu), \\
M P U=A(1-\alpha) \tilde{k}^{\alpha}\left[\mu+(1-\mu) \tilde{s}^{\rho}\right]^{\frac{1-\rho}{\rho}} \mu,
\end{gathered}
$$

with $\tilde{k} \equiv k / l$ and $\tilde{s} \equiv s / u$.

To simplify notation, hereafter we omit the $(*)$ notation for equilibrium values and set $B=1$. The model implies in steady state (balanced growth path):

$$
\begin{gathered}
M P K=p\left(\frac{1}{\beta}-(1-\delta)\right), \\
M P U \hat{z}+x=\beta M P S \hat{z} x^{\phi}, \\
1=\beta M P S E(z \mid z \geq \hat{z}) \phi x^{\phi-1} .
\end{gathered}
$$

Notice that equation (21) sets the stationary ratio of capital to labor as a function of preference and technology parameters, TFP and the barrier to capital accumulation: $\tilde{k} \equiv C(A, p)$. Hence, we can rewrite (19) and (20) as

$$
M P S=T(A, P)\left[\mu+(1-\mu) \tilde{s}^{\rho}\right]^{\frac{1-\rho}{\rho}} \tilde{s}^{\rho-1}(1-\mu)
$$




$$
M P U=T(a, p)\left[\mu+(1-\mu) \tilde{s}^{\rho}\right]^{\frac{1-\rho}{\rho}} \mu,
$$

with $T(A, p) \equiv A(1-\alpha) C(A, p)^{\alpha}$. Clearly, $T(A, p)$ is strictly decreasing in $p$ and strictly increasing in $A$. Using equations (22) and (23), we can write

$$
1=\beta x^{\phi}\left(\frac{M P S}{M P U}\right) \quad\left[1-\phi \frac{E(z \mid z \geq \hat{z})}{\hat{z}}\right] .
$$

Given the CES technology, we have

$$
\frac{M P S}{M P U}=\frac{1-\mu}{\mu}[f(\hat{z})]^{\rho-1} x^{\phi(\rho-1)}
$$

where $f(\hat{z})$ is defined as

$$
f(\hat{z}) \equiv \frac{\int_{\hat{z}}^{\bar{z}} z d G(z)}{\int_{0}^{\hat{z}} z \cdot d G(z)}
$$

Note that the function $f(\hat{z})$ satisfies: $f^{\prime}<0, \lim _{\hat{z} \rightarrow 0} f(\hat{z})=+\infty$, and $\lim _{\hat{z} \rightarrow \infty} f(\hat{z})=0$.

Using (27) and (23) in equation (26), we get

$$
[f(\hat{z})]^{1-\rho}=\frac{\beta(1-\mu)}{\mu} T(A, p)^{\frac{\rho \phi}{1-\phi}} D(\hat{z})^{\rho \phi}\left[1-\phi \frac{E(z \mid z \geq \hat{z})}{\hat{z}}\right],
$$

where $D($.$) is an strictly increasing function of \hat{z}$.

Equation (28) allows us to establish the uniqueness and properties of the threshold $\hat{z}$. First, for $\rho \in[0,1)$ and from the properties of $f(\hat{z})$, the left-hand side is a non-increasing function of $\hat{z}$; for $\rho \in(0,1)$ the left-hand side is strictly decreasing, approaching 0 as $\hat{z} \rightarrow \infty$, and $\infty$ as $\hat{z} \rightarrow 0$. The right-hand side of (28) is monotonically increasing and eventually positive if two conditions are met. First, $\frac{E(z \mid z \geq \hat{z})}{\hat{z}}$ must be a decreasing function of $\hat{z}$. Lemma 1 below shows that this is indeed the case under log-concavity of the density $\mathrm{g}($.$) . Second,$ the right-hand side is eventually positive if

$$
\lim _{\hat{z} \rightarrow \bar{z}} \frac{E(z \mid z \geq \hat{z})}{\hat{z}}<\frac{1}{\phi}
$$

which is satisfied as the limit above equals 1. Hence, by the intermediate value theorem, there is a unique value $\hat{z}>0$ that solves (28). The fact that $x$ is strictly positive follows from this and the fact that marginal products are positive (equations (22) and (23)). 
Three properties of the solution follow. First, from (28), in the limiting case of $\rho=0$ (Cobb-Douglas case), the threshold $\hat{z}$ is independent of TFP and the barrier to capital accumulation. Second, as $\rho \in(0,1)$, an increase in TFP (or, a reduction in $p$ ) implies a reduction in the threshold $\hat{z}$ and vice-versa. Finally, the threshold is independent of TFP and the barrier to capital accumulation in the limiting case of $\phi=0$.

Lemma 1: $\frac{E(z \mid z \geq \hat{z})}{\hat{z}}$ is decreasing in $\hat{z}$ if the density $g($.$) is log-concave.$

Proof. Let

$$
\psi(\hat{z})=\frac{E(z \mid z \geq \hat{z})}{\hat{z}}
$$

Then, $\psi^{\prime}(\hat{z})<0$ iff

$$
\frac{\partial E(z \mid z \geq \hat{z})}{\partial \hat{z}}<\frac{E(z \mid z \geq \hat{z})}{\hat{z}}
$$

The derivative above is less than or equal to one by Proposition 2 in ? (?) iff

$$
\int_{\hat{z}}(1-G(\hat{z})) d z
$$

is $\log$-concave. Log-concavity of the density $\mathrm{g}\left(\right.$.) ensures this. Furthermore, $\frac{E(z \mid z \geq \hat{z})}{\hat{z}}>1$. Hence,

$$
\frac{\partial E(z \mid z \geq \hat{z})}{\partial \hat{z}} \leq 1<\frac{E(z \mid z \geq \hat{z})}{\hat{z}}
$$

and the result follows. 
Table 1: List of Countries

\begin{tabular}{|lc|lc|}
\hline Name & Code & Name & Code \\
\hline Albania & ALB & Latvia & LVA \\
Argentina & ARG & Lithuania & LTU \\
Australia & AUS & Luxembourg & LUX \\
Austria & AUT & Macao-China & MAC \\
Belgium & BEL & Mexico & MEX \\
Brazil & BRA & Netherlands & NLD \\
Bulgaria & BGR & New Zealand & NZL \\
Canada & CAN & Norway & NOR \\
Chile & CHL & Panama & PAN \\
Colombia & COL & Peru & PER \\
Croatia & HRV & Poland & POL \\
Czech Republic & CZE & Portugal & PRT \\
Denmark & DNK & Romania & ROM \\
Estonia & EST & Russian Federation & RUS \\
Finland & FIN & Serbia, Republic of & SRB \\
France & FRA & Singapore & SGP \\
Germany & GER & Slovak Republic & SVK \\
Greece & GRC & Slovenia & SVN \\
Hong Kong-China & HKG & Spain & ESP \\
Hungary & HUN & Sweden & SWE \\
Iceland & ISL & Switzerland & CHE \\
Indonesia & IDN & Thailand & THA \\
Ireland & IRL & Trinidad and Tobago & TTO \\
Israel & ISR & Tunisia & TUN \\
Italy & ITA & Turkey & TUR \\
Japan & JPN & United Arab Emirates-Dubai & ARE \\
Jordan & JOR & United Kingdom & GBR \\
Kazakhstan & KAZ & United States & USA \\
Korea, Republic of & KOR & Uruguay \\
Kyrgyz Republic & KGZ & & URY \\
\hline & & & \\
\hline
\end{tabular}


Table 2: Summary Statistics

\begin{tabular}{|lcccc|}
\hline Statistic & PISA Score & Unskilled & Enrollment & Output Per Worker \\
\hline & & & & \\
Cross-country Mean & 464 & 0.81 & 0.92 & 46,646 \\
Cross-country Median & 483 & 0.82 & 0.98 & 42,988 \\
Cross-country Standard Deviation & 57 & 0.09 & 0.10 & 26,034 \\
90th/10th ratio & 1.39 & 1.32 & 1.26 & 5.21 \\
80th/20th ratio & 1.24 & 1.19 & 1.18 & 3.51 \\
\hline Corr (x, Y/N) & 0.79 & -0.33 & 0.50 & 1.00 \\
\hline
\end{tabular}

Note: Entries show summary statistics for the data we consider. 'PISA Score' refers to the mean score of the PISA test for each country. For the correlation (Corr) in the last row, $x$ denotes each country's mean PISA score, fraction of unskilled workers, enrollment rates, and output per worker.

Table 3: Parameter Values

\begin{tabular}{|l|c|}
\hline Parameter & Value \\
\hline & \\
Discount factor $(\beta)$ & 0.966 \\
Population growth rate $\left(g_{L}\right)$ & 0.009 \\
Substitution elasticity $(1 /(1-\rho))$ & 1.50 \\
Capital share $(\alpha)$ & 0.33 \\
Depreciation rate $(\delta)$ & 0.074 \\
Share of unskilled labor $(\mu)$ & 0.32 \\
Skill curvature parameter $(\phi)$ & 0.34 \\
Talent curvature parameter $(\epsilon)$ & 0.26 \\
Gamma distribution $(\theta)$ & 17.6 \\
Gamma distribution $(\kappa)$ & 27.7 \\
\hline
\end{tabular}

Note: Entries show the values of the calibrated parameters for our benchmark economy. Values for the discount factor and the depreciation rate are at the annual frequency. See text for details. 
Table 4: Empirical Targets: Model and Data (U.S.)

\begin{tabular}{|lll|}
\hline Statistic & Model & Data \\
\hline Capital-to-output ratio & & \\
Investment rate & 0.8 & 0.8 \\
Fraction of unskilled workers & 0.27 & 0.27 \\
Expenditure per tertiary student (\% GDP per worker) & 0.48 & 0.48 \\
Skill premium & 1.88 & 29 \\
Mean math score & 487 & 487 \\
Coefficient of variation math score & 0.19 & 0.19 \\
\hline & & \\
PISA Distribution & & \\
Median & 481 & 488 \\
10th percentile & 373 & 368 \\
25th percentile & 422 & 425 \\
75th percentile & 546 & 551 \\
90th percentile & 607 & 609 \\
\hline
\end{tabular}

Note: Entries in the top panel show the values for the U.S. statistics used as targets for our benchmark economy. Values for the capital-to-output ratio and the investment rate are at the annual frequency. Entries in the bottom panel show the data values for the talent distribution and the resulting values from its approximation via a gamma distribution.

Table 5: Model Mechanics

\begin{tabular}{|lcccc|}
\hline & $\begin{array}{c}\text { Fraction } \\
\text { Unskilled }\end{array}$ & $\begin{array}{c}\text { Quality } \\
(h)\end{array}$ & $\begin{array}{c}\text { Wage Premium } \\
\left(W_{s} / W_{u}\right)\end{array}$ & Output \\
\hline & & & & \\
Benchmark & 100.0 & 100.0 & 100.0 & 100.0 \\
Reduction in means (A) & 100.7 & 97.2 & 102.9 & 91.9 \\
Increase in dispersion (B) & 101.0 & 100.4 & 100.0 & 100.2 \\
Reduction in TFP (C) & 114.4 & 63.8 & 156.5 & 25.8 \\
A-C combined & 113.1 & 62.4 & 160.8 & 23.8 \\
\hline
\end{tabular}

Note: Entries show the values of variables across steady states in response to a reduction in mean PISA scores (A), an increase in dispersion in PISA scores (B), a reduction in TFP $(\mathrm{C})$, and joint changes in all of them (A-C combined). 
Table 6: Variation in PISA Scores

\begin{tabular}{|c|c|c|c|}
\hline & \multicolumn{3}{|c|}{ Ratio of Poor to Rich Countries } \\
\hline & $\frac{\text { Bottom } 10 \%}{\text { Top } 10 \%}$ & $\frac{\text { Bottom } 20 \%}{\text { Top } 20 \%}$ & $\frac{\text { Bottom } 25 \%}{\text { Top } 25 \%}$ \\
\hline$\%$ Unskilled & & & \\
\hline Model & 103.1 & 102.4 & 102.3 \\
\hline Data & 117.0 & 115.2 & 112.9 \\
\hline Output per Worker & & & \\
\hline Model & 89.7 & 91.1 & 90.9 \\
\hline Data & 12.1 & 17.3 & 19.7 \\
\hline Augmented talent $(h)$ & 96.5 & 97.1 & 97.1 \\
\hline Labor quality $(l)$ & 89.1 & 91.1 & 90.9 \\
\hline Capital $(K)$ & 89.7 & 91.1 & 90.9 \\
\hline TFP & 100.0 & 100.0 & 100.0 \\
\hline
\end{tabular}

Note: Entries show the values of variables across steady states in response to changes in the distribution of talent according to PISA data. Data for output per worker and the fraction of unskilled workers are shown for comparison. Entries are ratios of averages of each variable within percentiles at the top and bottom of the distribution of countries by output per worker. See text for details. 
Table 7: Variation in TFP and PISA Scores

\begin{tabular}{|lccc|}
\hline & \multicolumn{3}{c|}{ Ratio of Poor to Rich Countries } \\
\hline & $\frac{\text { Bottom 10\% }}{\text { Top 10\% }}$ & $\frac{\text { Bottom 20\% }}{\text { Top 20\% }}$ & $\frac{\text { Bottom 25\% }}{\text { Top 25\% }}$ \\
\% Unskilled & & & \\
$\begin{array}{l}\text { Model } \\
\text { Data }\end{array}$ & 120.4 & 116.6 & 115.2 \\
Output per Worker & 117.0 & 113.6 & 112.9 \\
Model & & & \\
Data & 12.1 & 17.3 & 19.7 \\
Augmented talent $(h)$ & 12.1 & 17.3 & 19.7 \\
Labor quality $(l)$ & 59.0 & 55.4 & 57.8 \\
Capital $(K)$ & 55.5 & 63.4 & 64.8 \\
TFP & 10.6 & 16.1 & 17.6 \\
\hline
\end{tabular}

Note: Entries show the values of variables across steady states in response to changes in the distribution of talent according to PISA data and technology (TFP and barrier to capital accumulation). TFP values are chosen to replicate exactly the level of output per worker in each country. Data for output per worker and the fraction of unskilled workers are shown for comparison. Entries are ratios of averages of each variable within percentiles at the top and bottom of the distribution of countries by output per worker. See text for details. 
Table 8: Matching the Division of Labor

\begin{tabular}{|c|c|c|c|}
\hline & \multicolumn{3}{|c|}{ Ratio of Poor to Rich Countries } \\
\hline & $\frac{\text { Bottom } 10 \%}{\text { Top } 10 \%}$ & $\frac{\text { Bottom } 20 \%}{\text { Top } 20 \%}$ & $\frac{\text { Bottom } 25 \%}{\text { Top } 25 \%}$ \\
\hline \multicolumn{4}{|l|}{ \% Unskilled } \\
\hline Model & 117.0 & 116.2 & 112.9 \\
\hline Data & 117.0 & 116.2 & 112.9 \\
\hline \multicolumn{4}{|l|}{ Output per Worker } \\
\hline Model & 12.1 & 17.3 & 19.7 \\
\hline Data & 12.1 & 17.3 & 19.7 \\
\hline Augmented talent $(h)$ & 50.1 & 56.3 & 58.7 \\
\hline Labor quality $(l)$ & 45.4 & 58.0 & 60.2 \\
\hline Capital $(K)$ & 10.6 & 16.1 & 17.6 \\
\hline TFP & 41.1 & 47.0 & 49.6 \\
\hline Investment Efficiency $B$ (Rich) & 45 & 45 & 44 \\
\hline Inv. Efficiency $B$ (Poor) & 29 & 31 & 33 \\
\hline
\end{tabular}

Note: Entries show the values of variables across steady states in response to changes in the distribution of talent according to PISA data, TFP, investment efficiency $(B)$, and the rest of exogenous variation across countries. TFP values and investment efficiency levels $(B)$ are chosen to replicate exactly the level of output per worker and the fraction of unskilled workers in each country. Data for output per worker and the fraction of unskilled workers are shown for comparison. Entries are ratios of averages of each variable within percentiles at the top and bottom of the distribution of countries by output per worker. See text for details. 
Table 9: Comparison with One-Sector Growth Model

\begin{tabular}{|c|c|c|c|}
\hline & \multicolumn{3}{|c|}{ Ratio of Poor to Rich Countries } \\
\hline & $\frac{\text { Bottom } 10 \%}{\text { Top } 10 \%}$ & $\frac{\text { Bottom } 20 \%}{\text { Top } 20 \%}$ & $\frac{\text { Bottom } 25 \%}{\text { Top } 25 \%}$ \\
\hline Panel A: Growth Model & & & \\
\hline Labor quality $(l)$ & 85.9 & 86.9 & 88.6 \\
\hline Capital $(K)$ & 10.6 & 16.1 & 17.6 \\
\hline TFP & 28.0 & 34.4 & 37.2 \\
\hline $\begin{array}{l}\text { Panel B: Variation in } \\
\text { TFP and PISA Scores }\end{array}$ & & & \\
\hline Labor quality $(l)$ & 55.5 & 63.4 & 64.8 \\
\hline Capital $(K)$ & 10.6 & 16.1 & 17.6 \\
\hline TFP & 37.2 & 43.3 & 46.6 \\
\hline Panel $C$ : Matching & & & \\
\hline Division of Labor & & & \\
\hline Labor quality $(l)$ & 45.4 & 58.0 & 60.2 \\
\hline Capital $(K)$ & 10.6 & 16.1 & 17.6 \\
\hline TFP & 41.1 & 47.0 & 49.6 \\
\hline
\end{tabular}

Note: Entries compare the values of variables across steady states in the onesector growth model with the Mincerian notion of labor quality, with values in our model. Panel B and Panel $\mathrm{C}$ entries repeat the values in previous tables for our model under two cases. See text for details.

Table 10: TFP Elasticity of Output per Worker

\begin{tabular}{|cccc|}
\hline $\begin{array}{c}\text { Growth Model } \\
\text { (Mincer) }\end{array}$ & $\begin{array}{c}\text { Growth Model } \\
\text { (PISA) }\end{array}$ & $\begin{array}{c}\text { This Paper: Variation in } \\
\text { PISA Scores and TFP }\end{array}$ & $\begin{array}{c}\text { This Paper: Matching } \\
\text { Division of Labor }\end{array}$ \\
\hline 1.7 & 1.8 & 2.1 & 2.2 \\
\hline
\end{tabular}

Note: Entries report the elasticities of output per worker with respect to TFP in the standard growth model under the Mincerian notion of labor quality, the growth model when labor quality is the mean value of PISA score, and in our model under the 'Variation in PISA Scores and TFP' specification and the 'Matching the Division of Labor' specification. See text for details. 
Table 11: Implications for Skill Premia

\begin{tabular}{|lccc|}
\hline & Ratio of Poor to Rich Countries \\
\hline & $\frac{\text { Bottom 10\% }}{\text { Top } 10 \%}$ & $\frac{\text { Bottom 20\% }}{\text { Top } 20 \%}$ & $\frac{\text { Bottom } 25 \%}{\text { Top } 25 \%}$ \\
& & & \\
Panel A: Data & & & \\
(restricted sample) & & & \\
\% Unskilled & 133.3 & 121.3 & 116.0 \\
Skill premium & 244.1 & 205.5 & 201.5 \\
\hline & & & \\
Panel B: Variation in & & & \\
TFP and PISA Scores & & & \\
\% Unskilled & 116.1 & 114.6 & 108.3 \\
Augmented talent $(h)$ & 56.1 & 59.8 & 68.9 \\
Skill premium & 102.7 & 102.8 & 110.5 \\
\hline & & & \\
Panel C: Matching & & & \\
Division of Labor & & & \\
\% Unskilled & 133.3 & 121.3 & 116.0 \\
Augmented talent $(h)$ & 56.3 & 60.2 & 63.8 \\
Skill premium & 215.4 & 158.8 & 144.3 \\
\hline
\end{tabular}

Note: Entries compare the values of variables across steady states in our model under the scenarios considered previously when data pertain to the restricted sample of countries. Panel B shows the implications when the PISA distribution varies across countries and TFP is chosen to reproduce output per worker across countries. Panel $\mathrm{C}$ shows the implications when, in addition, investment efficiency $(B)$ is chosen to reproduce the fraction of unskilled workers in each country. See text for details. 
Table 12: Sensitivity

\begin{tabular}{|lccc|}
\hline & \multicolumn{3}{c|}{ Ratio of Poor to Rich Countries } \\
\hline & $\frac{\text { Bottom } 10 \%}{\text { Top } 10 \%}$ & $\frac{\text { Bottom } 20 \%}{\text { Top } 20 \%}$ & $\frac{\text { Bottom } 25 \%}{\text { Top } 25 \%}$ \\
Panel A: Variation in & & & \\
PISA Scores and TFP & & & \\
Labor quality & 55.5 & 63.4 & 64.7 \\
TFP & 37.2 & 43.3 & 46.6 \\
\hline & & & \\
Panel B: $\phi=0$ & 95.2 & 93.0 & 92.7 \\
Labor quality & 27.0 & 33.2 & 36.5 \\
TFP & & & \\
\hline & & & \\
Panel C: $\epsilon=1$ & 43.3 & 49.5 & 51.1 \\
Labor quality & 44.1 & 49.7 & 53.4 \\
TFP & & & \\
\hline & & & \\
Panel D: High Substitution & & & \\
Elasticity & 50.1 & 59.9 & 61.3 \\
Labor quality & 37.6 & 43.8 & 47.1 \\
TFP &
\end{tabular}

Note: Entries compare the values of variables across steady states under different cases. Panel A shows the benchmark case 'Variation in PISA Scores and TFP'. Panel B shows the case when there are no investments in skills $(\phi=0)$ and TFP values are chosen to reproduce output per worker. Panel C shows the case when our notion of talent is equal to the PISA score $(\epsilon=1)$. Panel D shows the case when the elasticity of substitution between skilled and unskilled is higher than in the benchmark (2.5 instead of 1.5). See text for details. 